Revue des patrimoines

\title{
L'habitat rural des vallées de la Baïse et du Lot : contexte agraire et paysager
}

\section{Hélène Mousset}

\section{(2) OpenEdition}

Journals

Édition électronique

URL : http://journals.openedition.org/insitu/2337

DOI : 10.4000/insitu.2337

ISSN : 1630-7305

\section{Éditeur}

Ministère de la culture

Référence électronique

Hélène Mousset, «L'habitat rural des vallées de la Baïse et du Lot : contexte agraire et paysager », In Situ [En ligne], 5 | 2004, mis en ligne le 19 avril 2012, consulté le 02 mai 2019. URL : http:// journals.openedition.org/insitu/2337 ; DOI : 10.4000/insitu.2337

Ce document a été généré automatiquement le 2 mai 2019.

\section{(c) (i) (9)}

In Situ Revues des patrimoines est mis à disposition selon les termes de la licence Creative Commons Attribution - Pas d'Utilisation Commerciale - Pas de Modification 4.0 International. 


\section{L'habitat rural des vallées de la Baïse et du Lot : contexte agraire et paysager}

\section{Hélène Mousset}

Figure 1

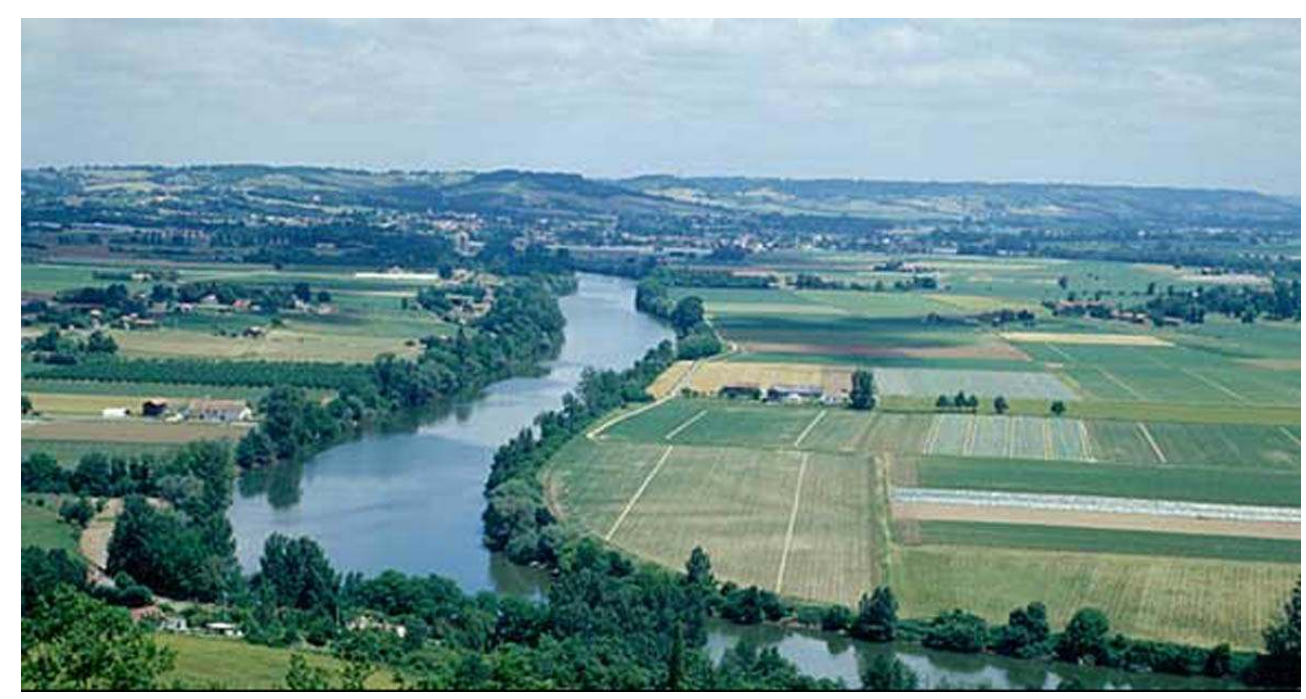

Bourran. Paysage. Vue de la plaine du Lot à Bourran, depuis le sommet du Pech de Berre vers le nordest

Phot. Inv. M. Dubau @ Inventaire général, ADAGP, 19982000

L'inventaire des vallées du Lot et de la Baïse est lié au projet de remise en navigation des deux rivières ${ }^{1}\left(\right.$ fig. $\left.\mathbf{n}^{\circ} \mathbf{1}\right)$. Le territoire de l'enquête s'étend sur dix-sept cantons traversés ou bordés par ces rivières, espace essentiellement rural. Le contexte d'aménagement du territoire a orienté l'étude vers l'histoire de l'occupation du sol et la géographie historique. Les résultats se lisent d'abord dans l'apport conséquent et indéniable de connaissances inédites (bases Mérimée pour l'architecture et Palissy pour le mobilier)². 
En outre, l'opération montre à une échelle inusitée les possibilités de l'inventaire topographique fondé sur une enquête de terrain systématique et générale. La phase de collecte des données constituant le corpus est aujourd'hui achevée. Cet article tend à montrer la richesse de l'information récoltée, mais aussi la méthode d'analyse d'une réalité rurale dense et disparate. Après avoir situé l'enquête, les fermes - qui constituent la majeure partie de l'habitat des campagnes - seront présentées dans leur grande diversité, puis les autres édifices qui composent également l'espace rural.

\section{Le territoire et les conditions de l'enquête}

\section{Le territoire}

Figure 2

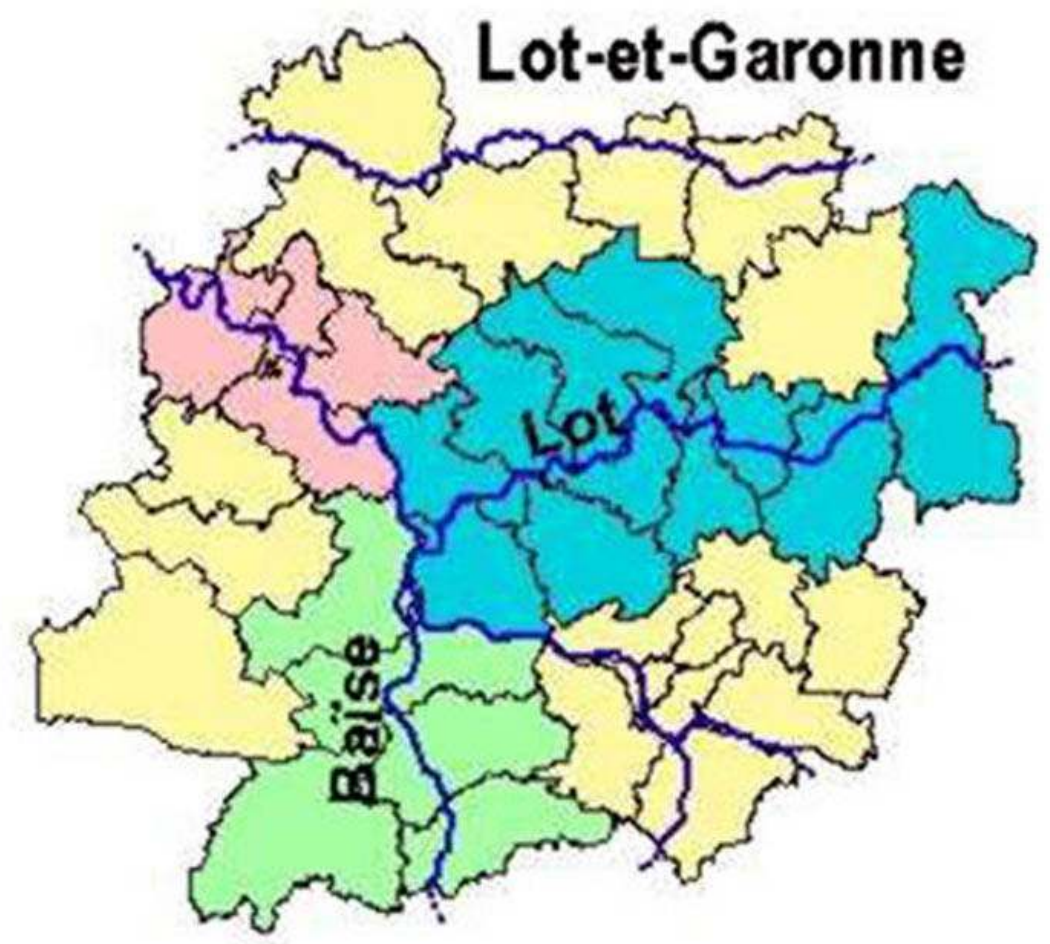

Carte du département du Lot-et-Garonne

Carte H. Mousset @ Inventaire général, H. Mousset, 2003

2 Le territoire inventorié prend en écharpe le département de Lot-et-Garonne ${ }^{3}$ du sudouest au nord-est et comprend plusieurs secteurs géographiques (fig. $n^{\circ} 2$ ). Lorsqu'on parcourt cet espace, la diversité des paysages apparaît comme une évidence : nuances topographiques, utilisations agricoles, implantation de l'habitat, matériaux de construction, etc.

3 Au nord du Lot, les Mollasses ou terreforts de l'Agenais forment un paysage de collines douces ponctuées de buttes (fig. $n^{\circ} 3$ ).

4 Au nord-est, les causses du Quercy commencent en Fumélois en un plateau calcaire très boisé (fig. $n^{\circ} 4$ ), dont les ressources naturelles ont attiré des industries rurales complétant les clairières de défrichement. 
Figure 3

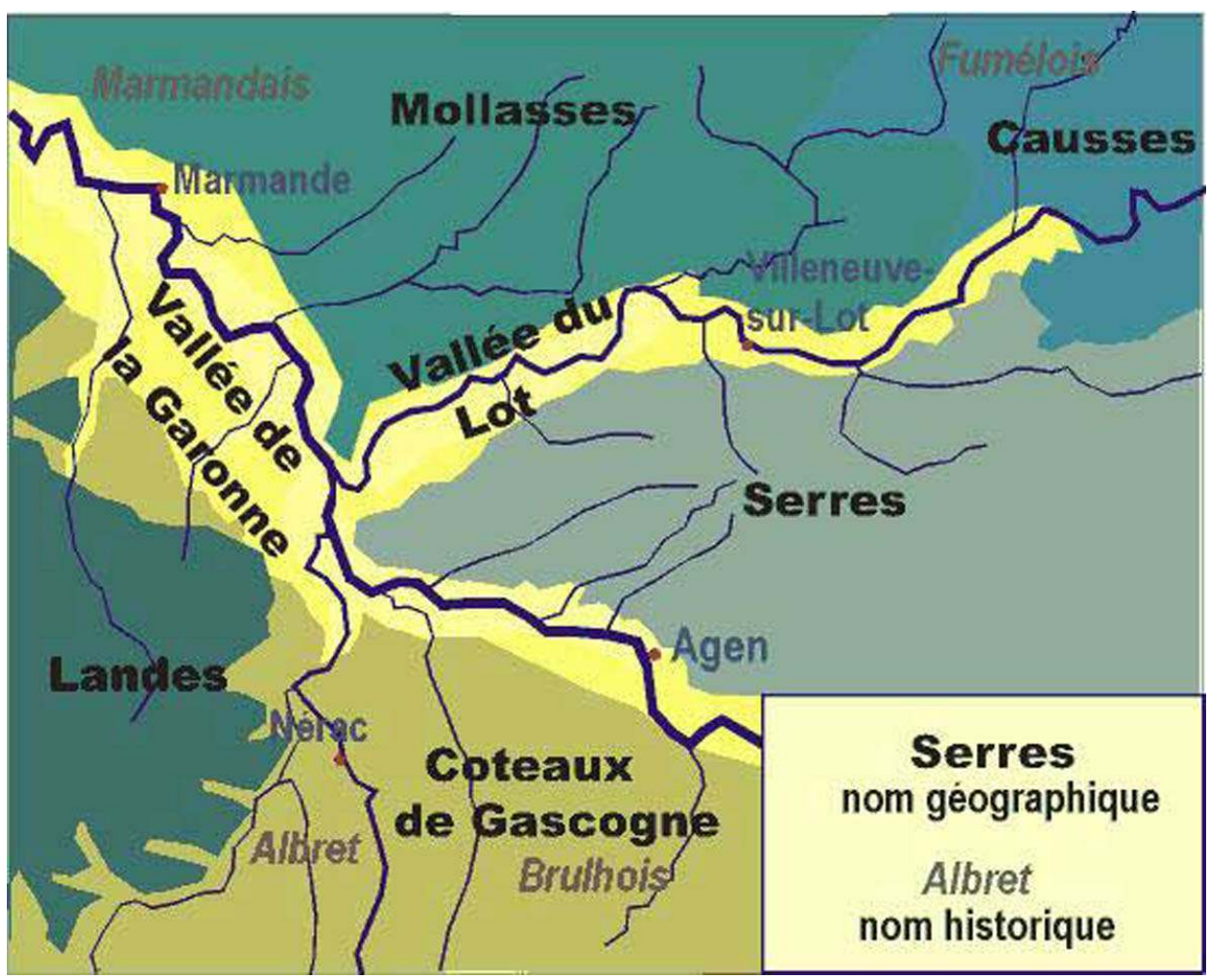

Carte schématique des secteurs géographiques autour du Lot et de la Baïse

Carte H. Mousset @ Inventaire général, H. Mousset, 2003 
Figure 4

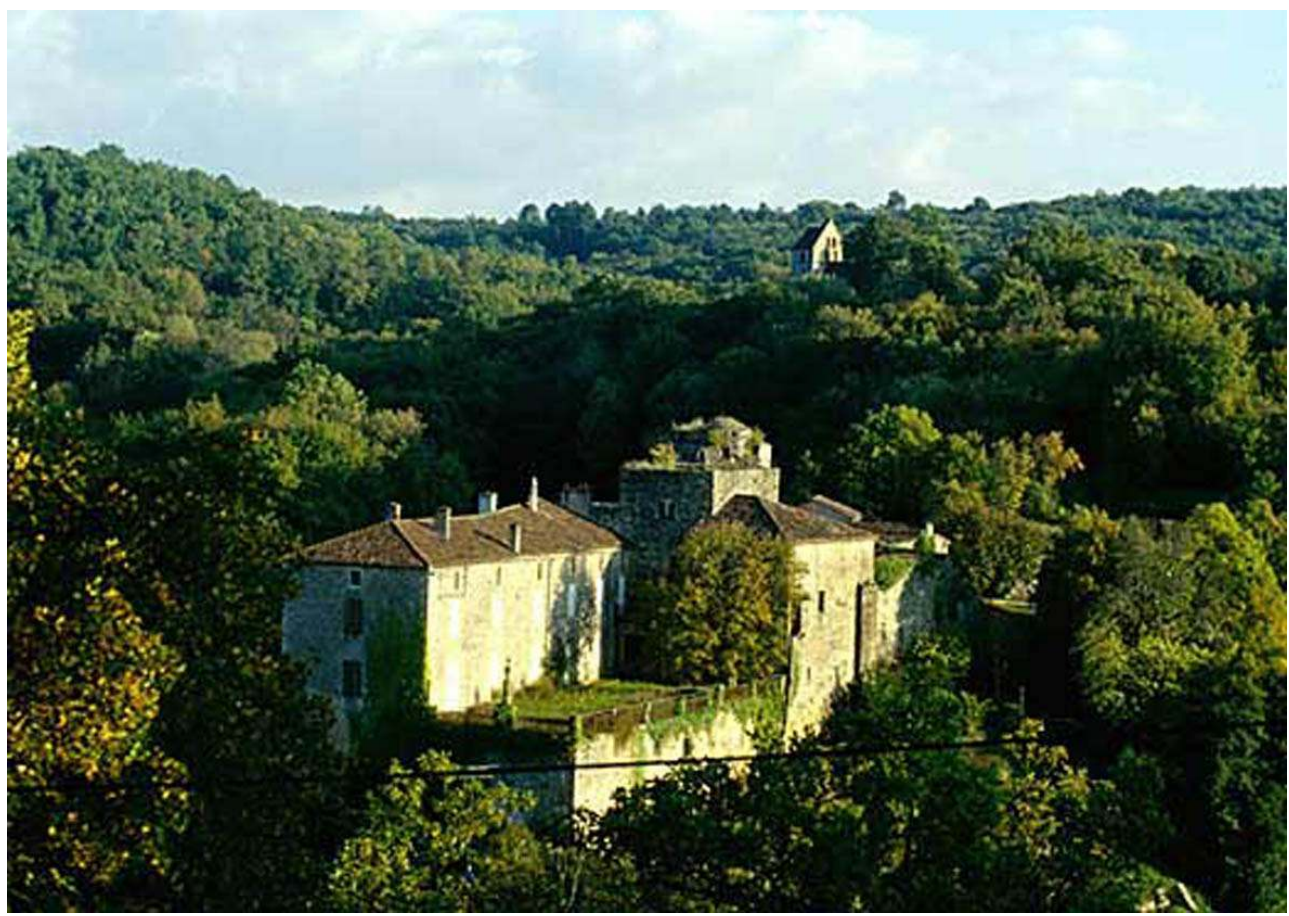

Blanquefort-sur-Briolance : château. Vue d'ensemble du château et de l'église Notre-Dame au dernier plan, depuis le nord-ouest

Phot. Inv. B. Chabot @ Inventaire général, ADAGP, 1996

\section{Figure 5}

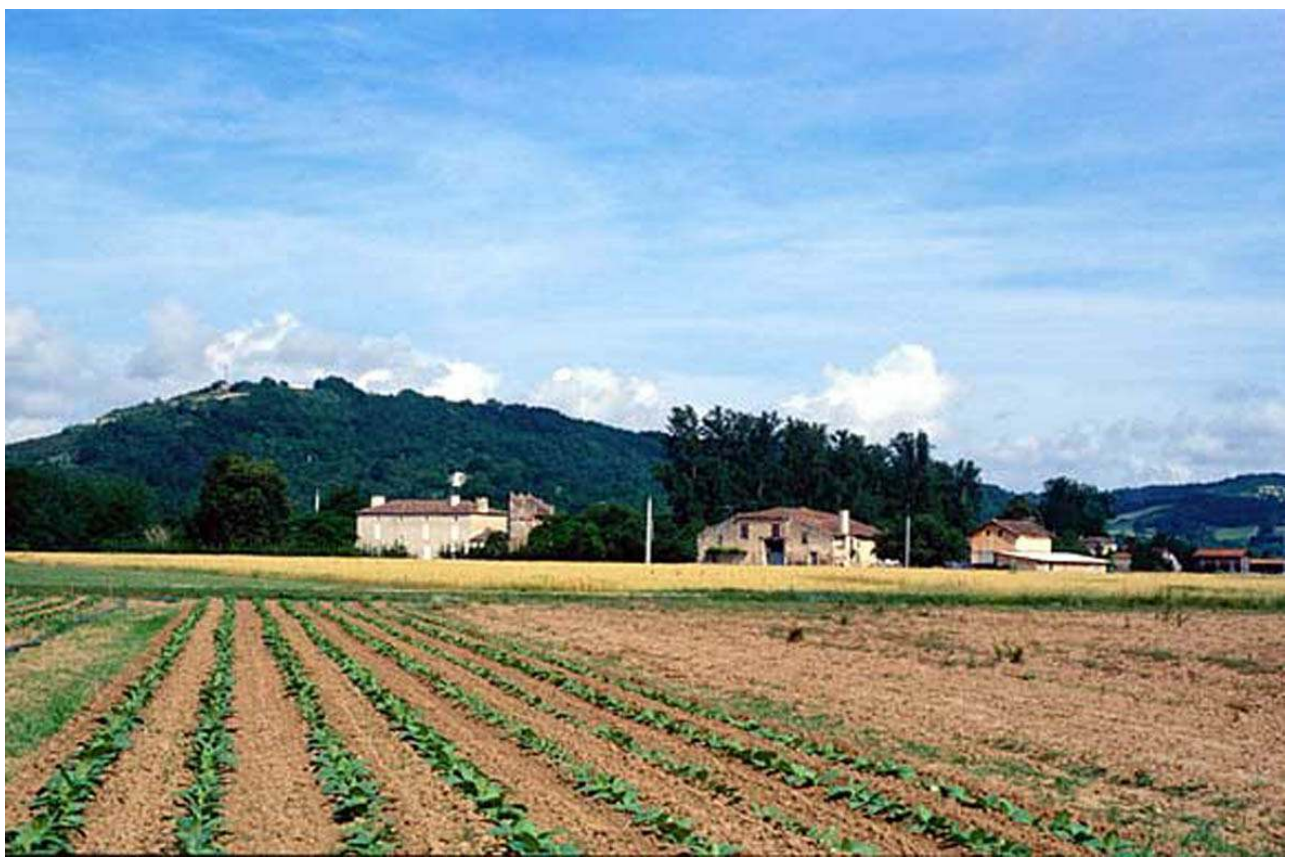

Aiguillon. Sainte-Radegonde, maison de maître. Vue du site avec la métairie depuis le sud-est Phot. Inv. M. Dubau ( ) Inventaire général, ADAGP, 1998 
La Garonne et le Lot ont ouvert deux amples vallées, de 3 à $4 \mathrm{~km}$ de large, où les crues ont apporté des limons fertiles (fig. $\mathbf{n}^{\circ}$ )

Entre Lot et Garonne, le relief marque le paysage au point de donner son nom à la région, les Serres : le plateau calcaire garde une surface tabulaire découpée de vallées encaissées et d'éperons bordés d'escarpements (fig. $\mathbf{n}^{\circ} \mathbf{6}$ ).

$7 \mathrm{Au}$ sud de la Garonne, la plus grande partie du territoire est constituée par les coteaux, plateaux calcaires érodés et découpés par les vallées coulant du sud au nord vers la gouttière garonnaise (fig. $\mathbf{n}^{\circ} \mathbf{7}$ ). Le sud-ouest appartient au paysage des landes: sols sableux recouverts par la forêt de pins plantée au 19e siècle en remplacement de bois aux essences variées (chênes-liège notamment).

\section{Figure 6}

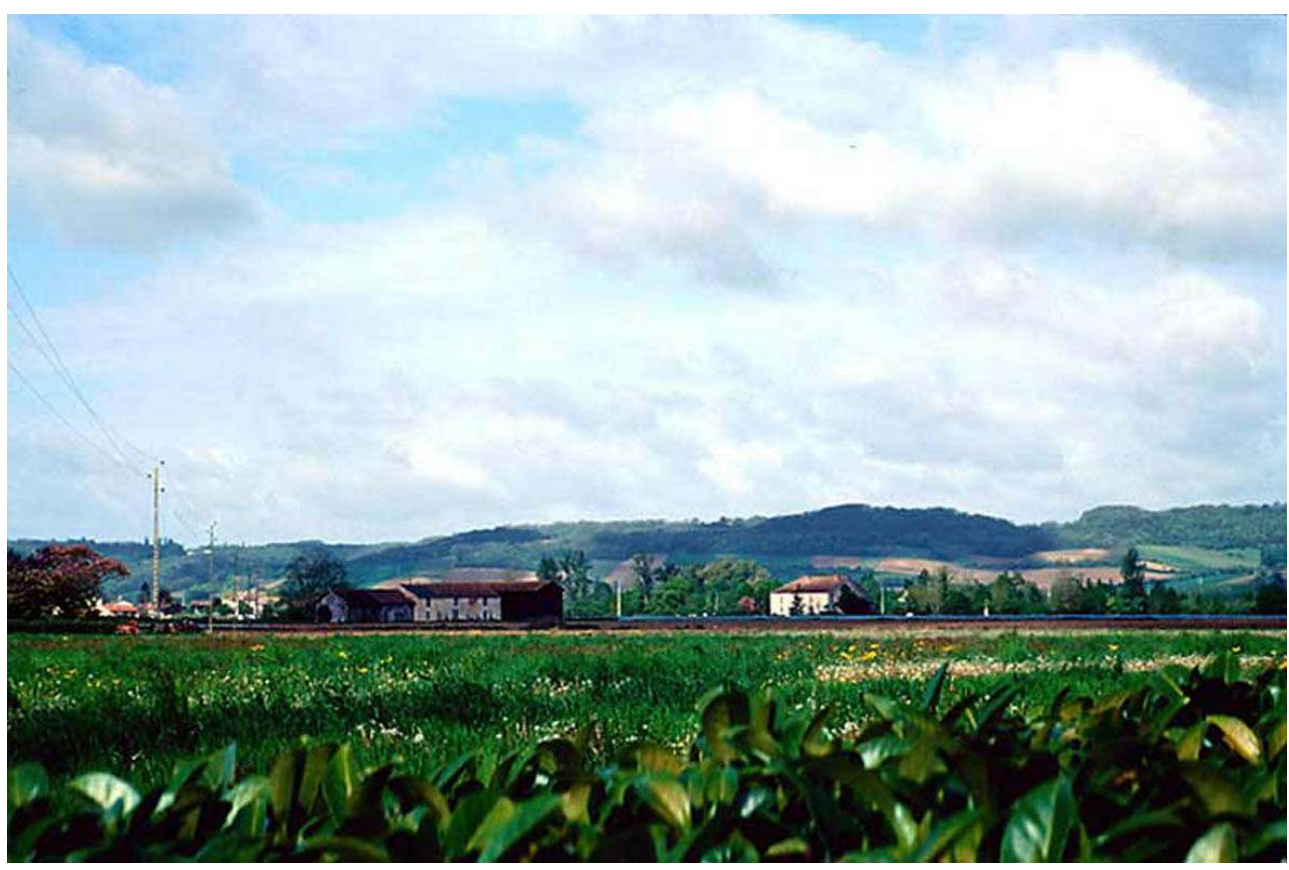

Port-Sainte-Marie. Paysage de la vallée du Lot à Bourran, vue prise du sud

Phot. Inv. H. Mousset ( Inventaire général, ADAGP, 2000 


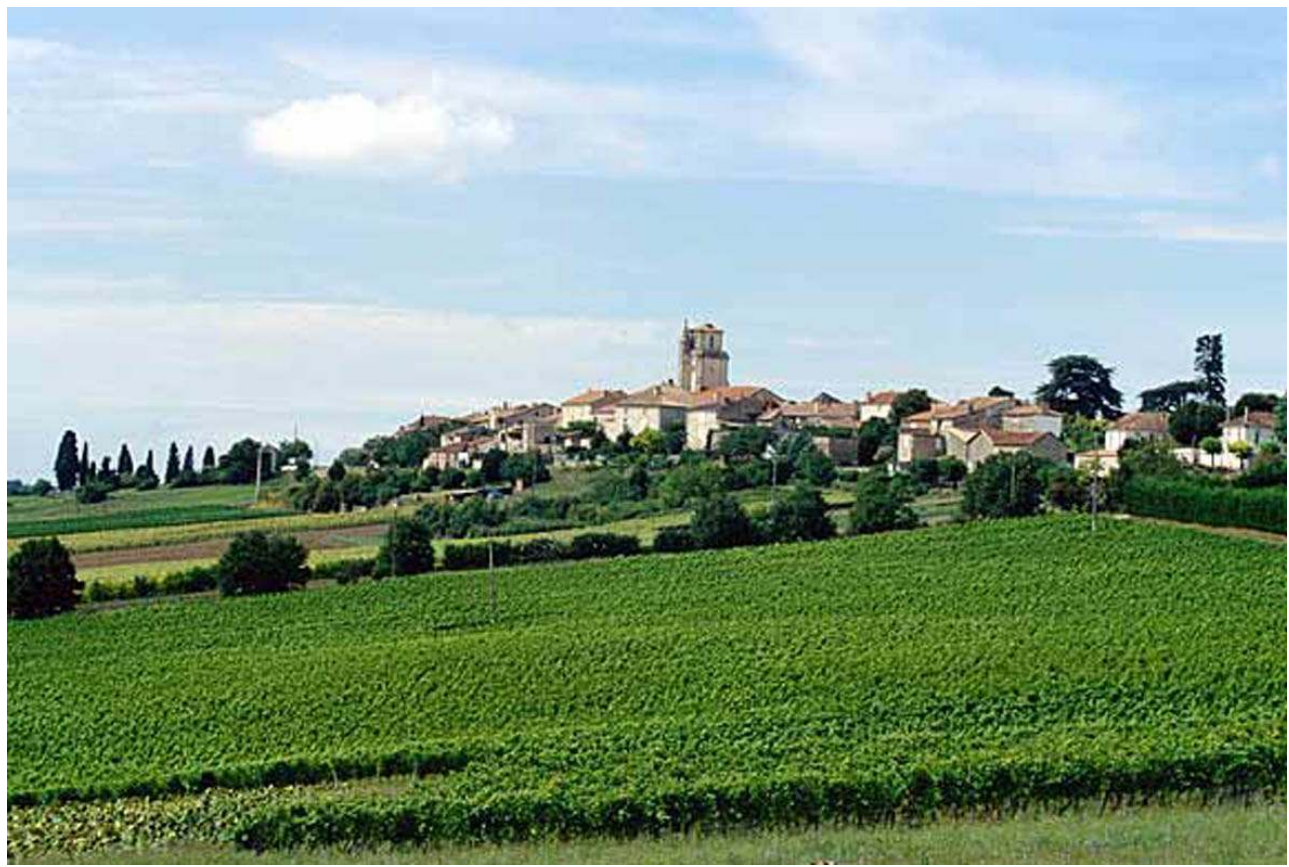

Montagnac-sur-Auvignon. Vue d'ensemble du village depuis le sud-est

Phot. Inv. B. Chabot @ Inventaire général, ADAGP, 1996

8 L'enquête a été menée en sept ans pour la vallée du Lot et cinq ans pour la Baïse, par trois personnes4. Plus qu'un recensement, il s'agit de la collecte d'éléments lisibles, précis, datés au mieux, permettant de comprendre l'occupation de l'espace. Mais l'étude des fermes dans un vaste territoire rural pose le double problème du très grand nombre et de la diversité. Des critères d'analyse ont été retenus en nombre restreint afin de ne pas retarder l'enquête - choix primordial dont dépendent les conclusions du repérage ${ }^{5}$. Les lignes en ont été dictées par l'orientation de l'étude : datation, matériaux de construction, dépendances, relations entre les parties agricoles et l'habitation... Les rapports entre le logis et ses dépendances étant longues à noter sur le terrain, mais essentielles pour comprendre la mise en valeur du sol, leur étude a été conduite à l'aide d'une typologie (voir ci-dessous).

9 L'historiographie du territoire présente deux synthèses un peu anciennes sur l'espace rural, par des géographes ${ }^{6}$, et des recherches historiques ponctuelles, sur un canton ou une ville, ou thématiques, par exemple sur les maisons à empilage, les églises romanes ou les bourgs castraux 7 . La démarche de l'Inventaire, complémentaire de ces études, consiste à la fois à intégrer les questions de la recherche historique dans ses propres interrogations et à y chercher des explications aux faits observés durant l'enquête.

Par ailleurs, une recherche est menée dans les archives : plans du XVIII ${ }^{e}$ siècle ou procèsverbaux d'époque révolutionnaire ${ }^{8}$ apportent une information précieuse sur les paysages et les systèmes agraires, à relier avec les observations de terrain. Sur les cartes de Belleyme et de Cassini du milieu du XVIII ${ }^{\mathrm{e}}$ siècle, figurent les chefs de paroisses, les maisons nobles, la végétation. Avec les cadastres "napoléoniens", une approche régressive plus systématique devient possible, portant sur l'organisation de l'habitat (hameaux disparus ou regroupés au cours du XIXe siècle) ou sur les cultures. 


\section{L'analyse de l'habitat rural : maisons et fermes}

\section{Habitat et paysages}

11 Maisons et fermes s'inscrivent en points forts, sites, volumes, matériaux, couleurs contribuant à qualifier les paysages. Le bilan patrimonial en offre une image actuelle, représentable sous forme cartographique'. Mais en intégrant l'information chronologique, l'habitat et ses dépendances constituent autant de repères de l'évolution paysagère.

Figure 8

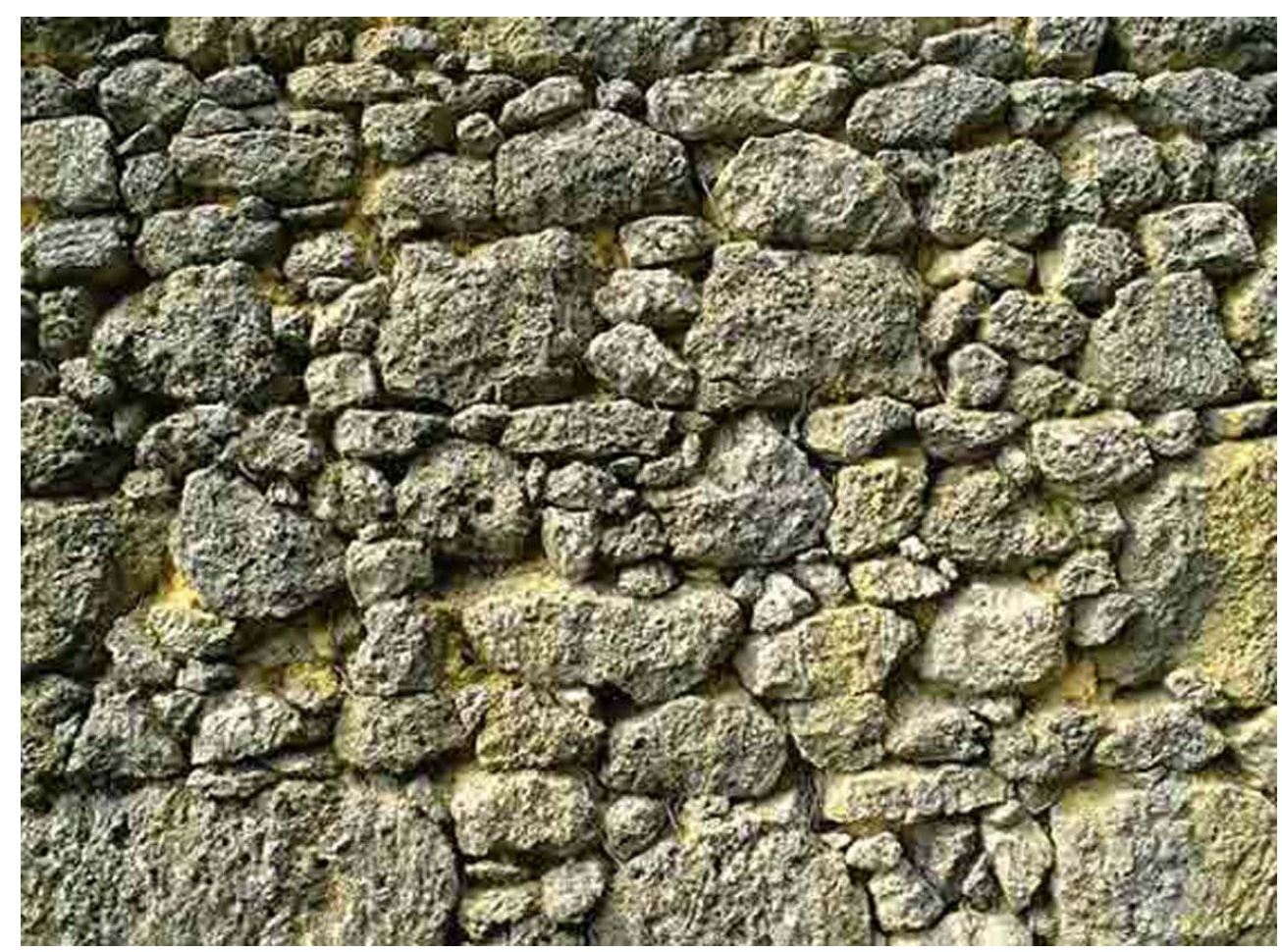

Moncrabeau Villandrau. Ferme. Détail de mise en œuvre du moellon

Phot. Inv. B. Chabot @ Inventaire général, ADAGP, 1995

12 Les matériaux de construction sont certes liés aux ressources du sol (fig. $\mathbf{n}^{\circ} \mathbf{8}$ ), mais parmi celles-ci s'opère un choix qui peut varier selon les époques. Les vallées de la Baïse et du Lot offrent des matières premières diverses, calcaire gréseux, terre crue, brique, bois, silex, galets), qui peuvent de plus être combinées de différentes manières (assises alternées, appareil mixte, etc.). Une brique de module épais se répand aux XIII-XIV ${ }^{\mathrm{e}}$ siècles dans la vallée du Lot et ne semble plus fabriquée au XVII siècle. L'appareil en assises alternées brique et pierre paraît à la mode aux XVII ${ }^{e}$ et XVIII ${ }^{e}$ siècles d'Aiguillon à Saint-Sylvestre.

13 L'ardoise, matériau importé, n'est utilisée que pour des demeures de propriétaires aisés aux XVIII et XIX ${ }^{e}$ siècles (fig. $\mathbf{n}^{\circ}$ 9). 
Les bâtiments apportent aux paysages des couleurs renouvelées par une technique ou une mode: la longue durée montre la relativité des déterminismes géographiques et l'importance des contextes historiques et sociaux ${ }^{10}$ (fig. $\left.\mathbf{n}^{\circ} \mathbf{1 0}\right)$.

Figure 9

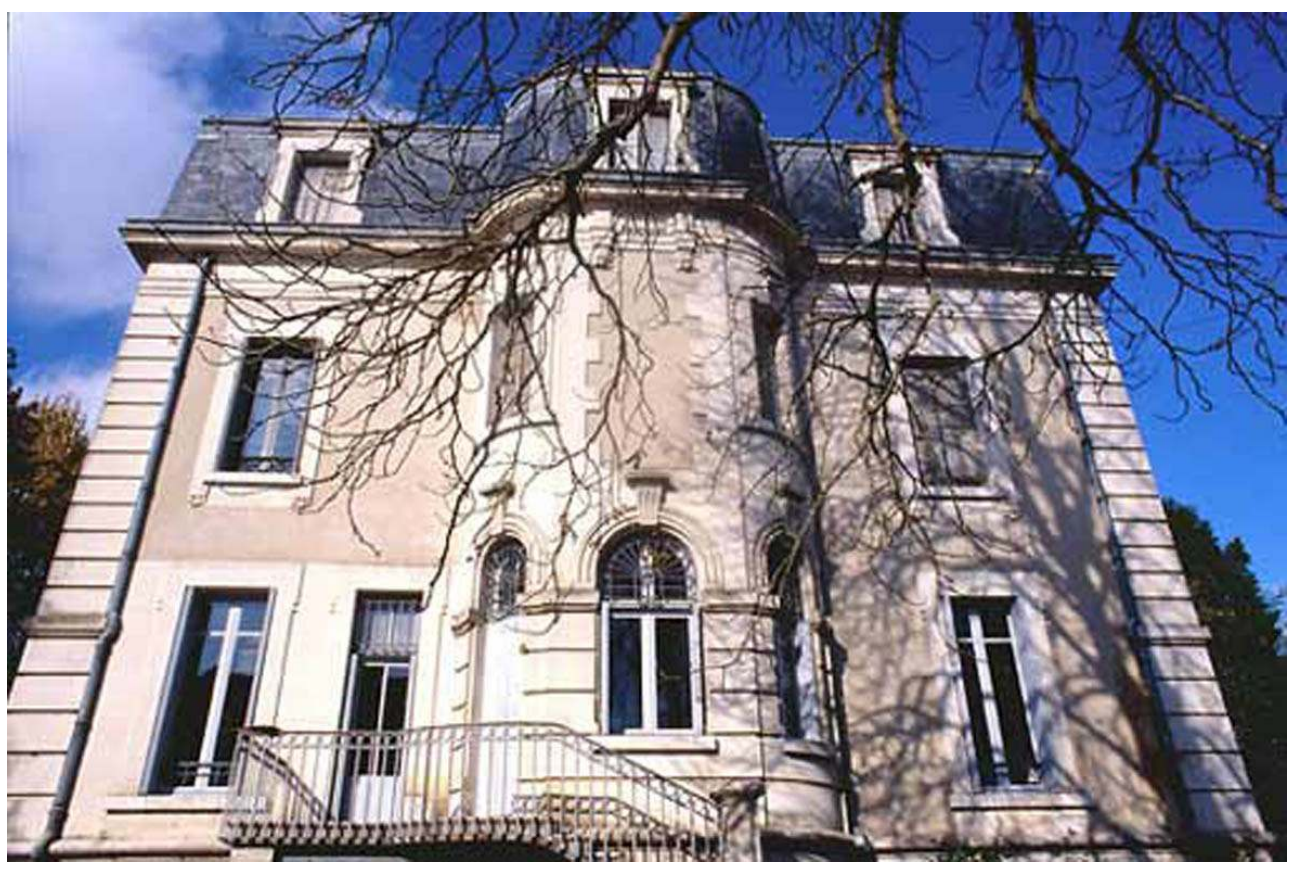

Lavardac. Gare. Maison de notable, dite Maison Dayraut. Elévation postérieure

Phot. Inv. M. Dubau (C) Inventaire général, ADAGP, 2000

Figure 10

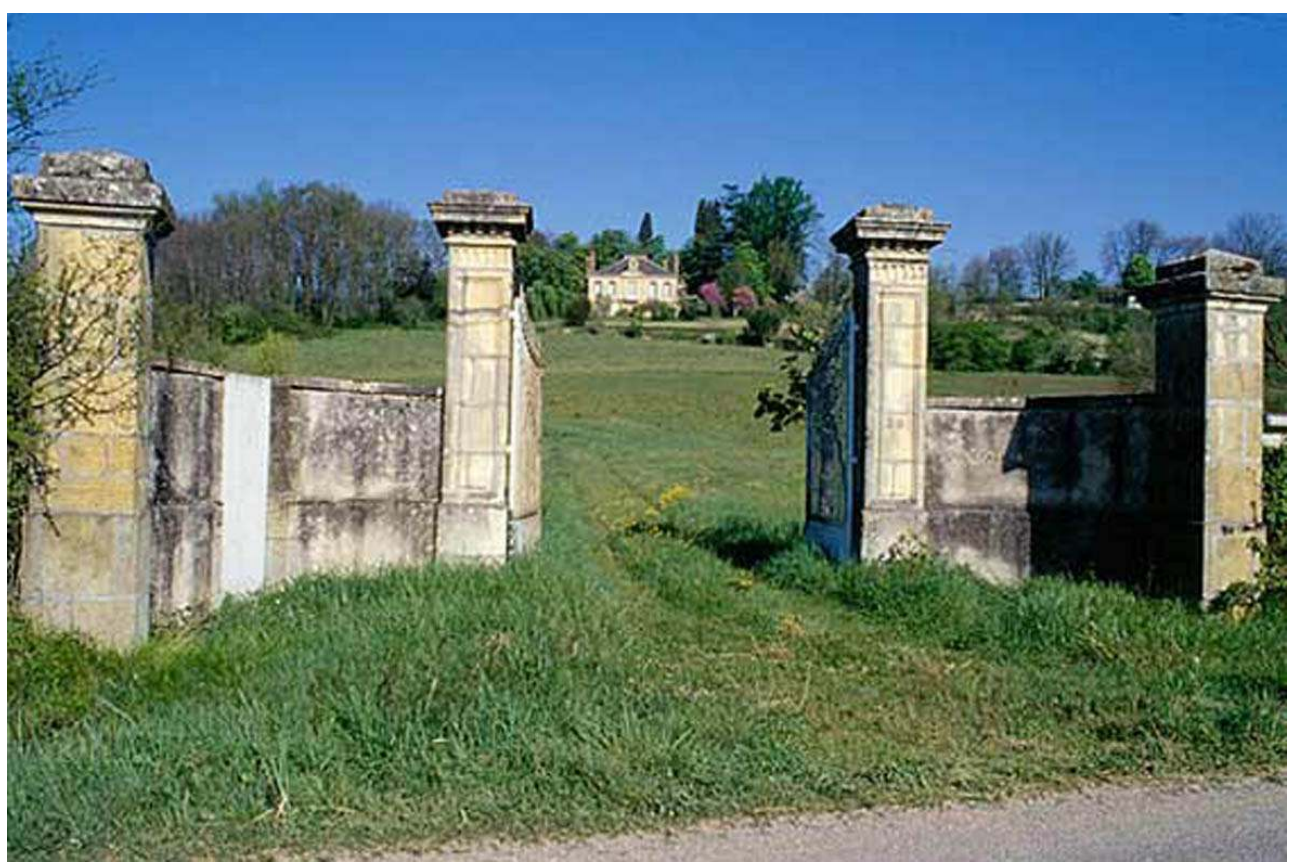

Monsempron-Libos. Roquefalco. Maison de maître. Vue d'ensemble du portail d'entrée et de la maison depuis le sud

Phot. Inv. B. Chabot @ Inventaire général, ADAGP, 1997 
Il en va de même des partis architecturaux. Prenons l'exemple des pigeonniers nombreux dans ce secteur du Sud-Ouest : les colombiers circulaires à trous de boulin de fond en comble étaient un privilège des terres nobles; les pigeonniers carrés fleurissent après la Révolution, et parmi ces derniers, les pigeonniers en double appentis (dits "en pied de mulet") se concentrent dans l'est du territoire, Fumélois et Brulhois, révélant l'influence toulousaine.

Figure 11

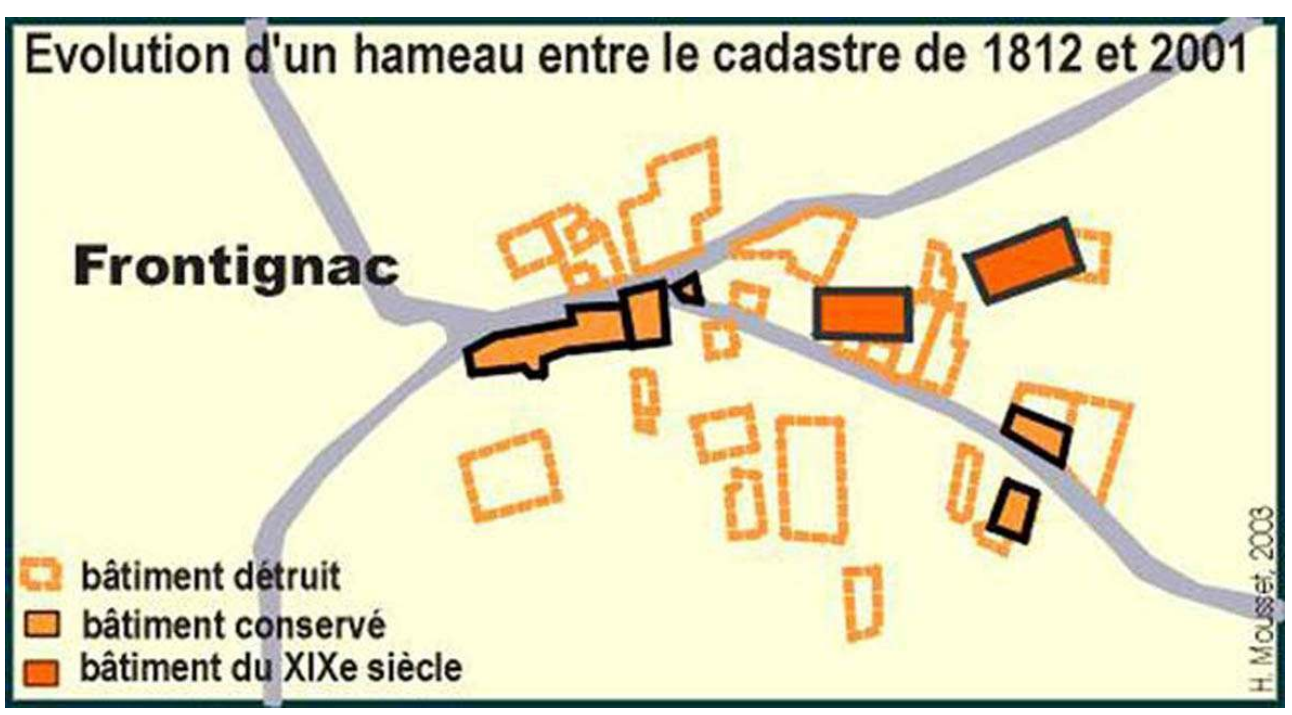

Frontignac. Evolution du hameau entre les cadastres de 1812 et 2001

Plan H. Mousset (c) Inventaire général, H. Mousset, 2003

Dans l'ensemble, les éléments observés sur l'habitat rural en Agenais couvrent une période allant $\mathrm{du} \mathrm{XV}^{\mathrm{e}}$ au $\mathrm{XX}^{\mathrm{e}}$ siècle - cinq siècles qui ont vu une transformation des édifices et des systèmes agraires. Sur site, certaines évolutions sont lisibles comme ces hameaux des Serres qui comptaient une dizaine à une vingtaine de feux (fig. $\left.\mathbf{n}^{\circ} \mathbf{1 1}\right)$; délaissés au XIXe siècle avec l'exode rural, ils ont été repris par une seule famille qui a regroupé terres et bâtiments, reconstruit une habitation plus confortable et converti les anciens logis en dépendances.

\section{Typologie et systèmes agraires}

La typologie principale des fermes s'appuie sur les relations entre l'habitation et les fonctions agricoles.

On a ainsi distingué les quatre types suivants :

- Logis bien distinct de ses dépendances (fig. $\mathbf{n}^{\circ} \mathbf{1 2}$ ) 
Figure 12

Logis distinct des dépendances
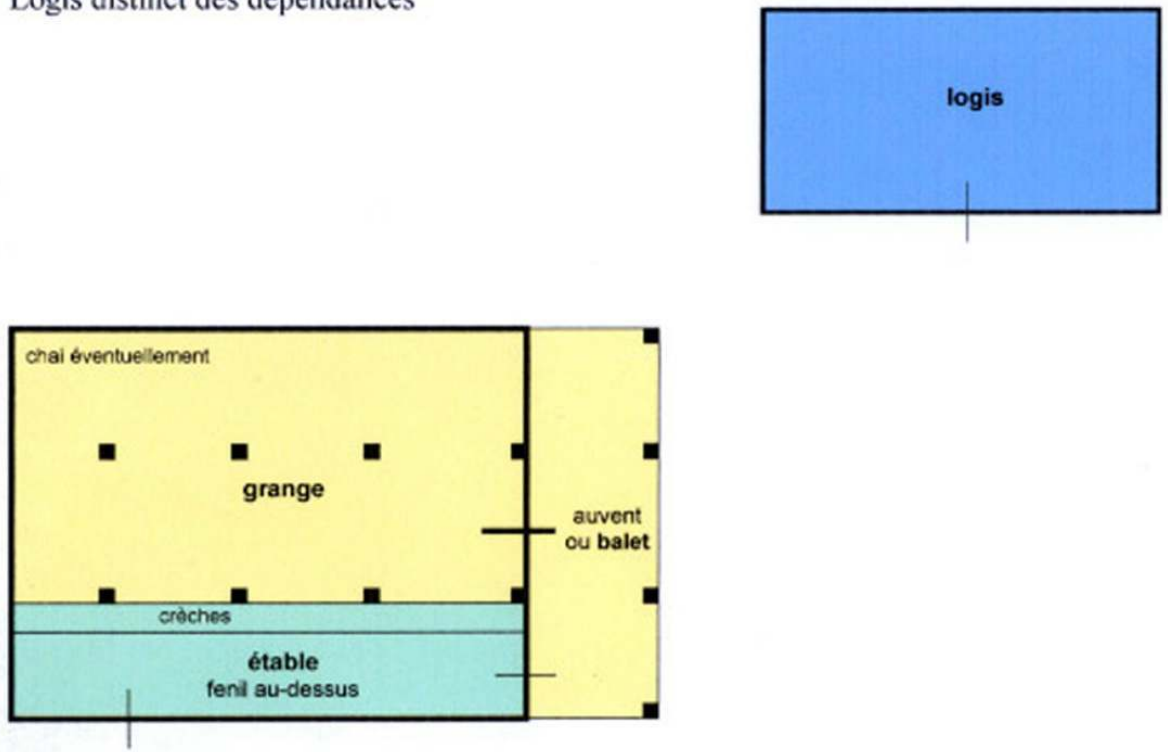

Typologie principale des fermes : logis distinct des dépendances

Schéma H. Mousset () Inventaire général, H. Mousset, 2003

20 La ferme isolée dotée d'un logis indépendant et immédiatement discernable est aujourd'hui l'image la plus courante des fermes agenaises. Il s'agit de logis de trois travées ordonnancées, en rez-de-chaussée avec comble à surcroît ouvert par des oculi ou fenestrous ou, plus rarement, à un étage carré. Ce modèle d'habitation aux pièces plus grandes et plus régulières apparaît dans les campagnes agenaises à la fin du XVII ${ }^{\mathrm{e}}$ siècle et se répand massivement au tournant des $\mathrm{XVIII}^{\mathrm{e}}$ et $\mathrm{XIX}^{\mathrm{e}}$ siècles, période de construction intense de logements neufs. Ce logis est accompagné au sud de la Garonne de dépendances adossées, corps de bâtiment sous appentis ou perpendiculaire sur l'arrière du logis, abritant grange, étable et chai (fig. $\mathbf{n}^{\circ} \mathbf{1 3}$ ). 
Figure 13

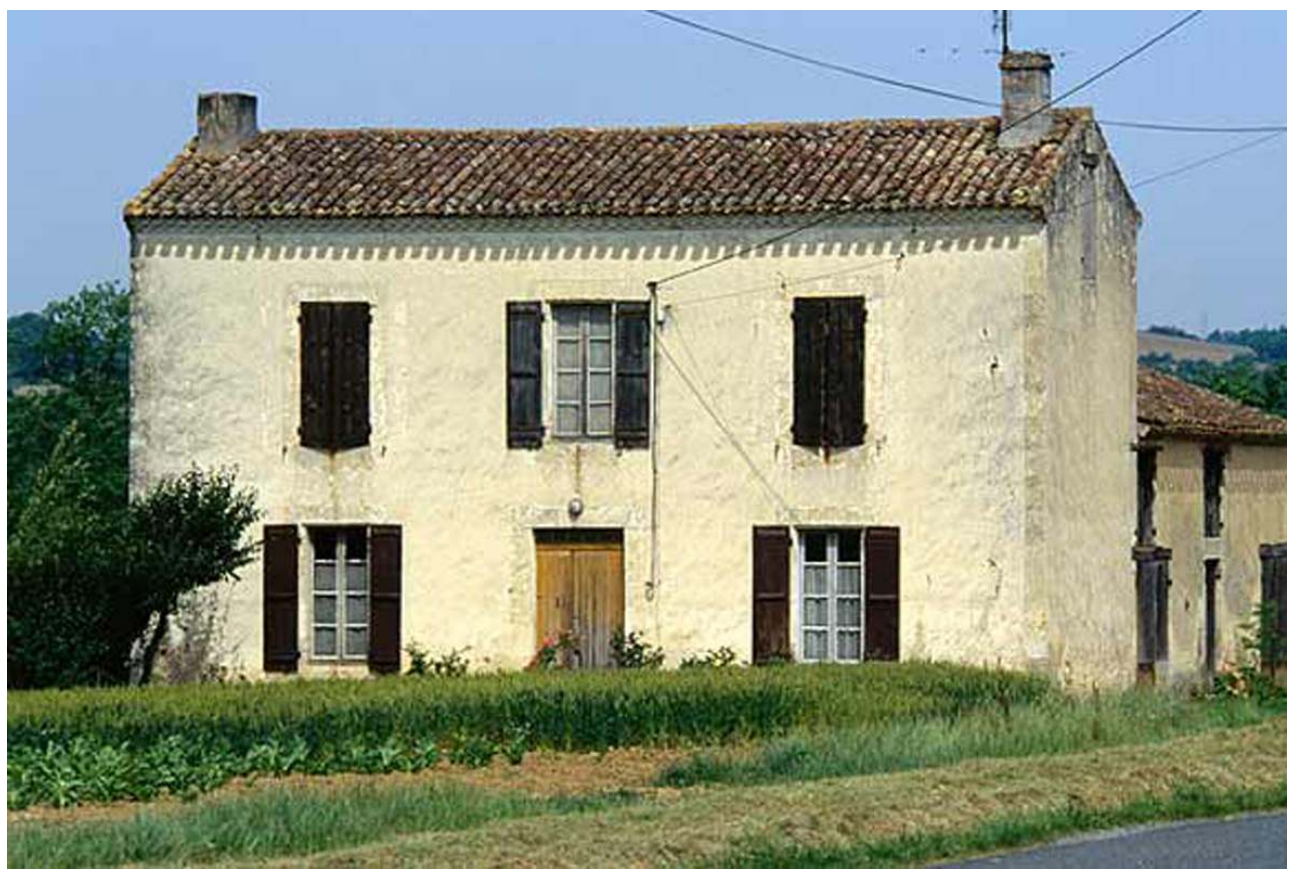

Lavardac. Ferme Dupont. Elévations antérieure et latérale

Phot. Inv. B. Chabot @ Inventaire général, ADAGP, 1995

21 Autour de la vallée du Lot, les dépendances sont isolées et dispersées près du logis. La principale est une grange-étable, complétée des fours à pain et à prunes. La composition ouverte de ces fermes offre de multiples variantes, limitées toutefois par l'orientation sud/sud-est du logis et sud-est/est de la grange, pour offrir des murs aveugles aux vents et aux pluies de nord-ouest. 


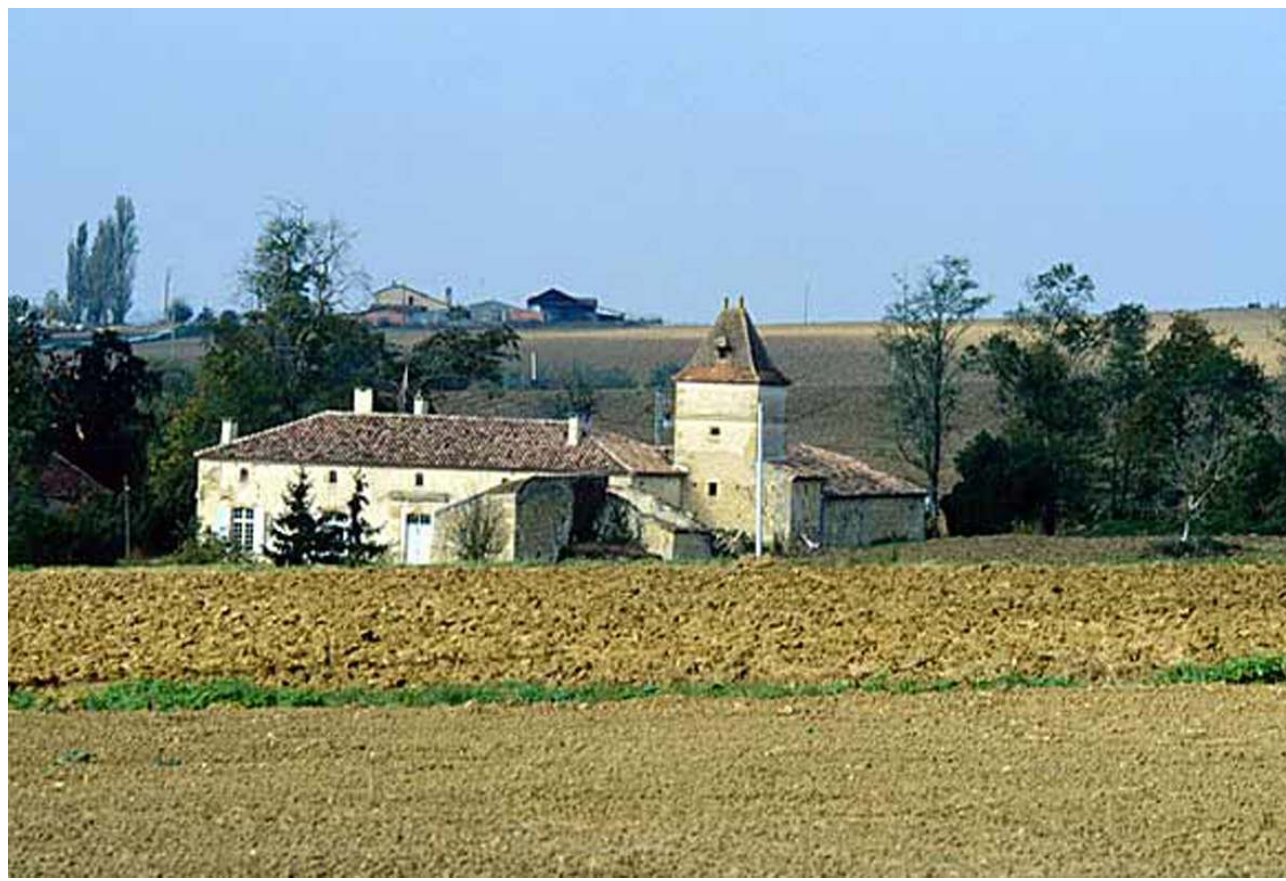

Saint-Vincent-de-Lamontjoie. Pradas. Ferme : vue d'ensemble depuis le nord-est

Phot. Inv. B. Chabot @ Inventaire général, ADAGP, 1997

22 Ce nouveau modèle de bâti agricole semble apparaitre à la fin du XVII ${ }^{e}$ siècle et devient courant à partir de la fin du XVIII et au XIX ${ }^{e}$ siècle. Il a souvent remplacé les hameaux en voie d'abandon, dont les anciens logis sont alors convertis en dépendances de la nouvelle ferme (fig. $\left.\mathbf{n}^{\circ} \mathbf{1 4}\right)$.

- Vaste bâtiment isolé abritant sous le même toit le logis et toutes les parties agricoles (fig. $n^{\circ}$ 15)

A l'inverse des bâtiments multiples et agglomérés des hameaux, les volumes des exploitations en un seul corps de bâtiment se détachent nettement dans le paysage. Ces fermes sont très courantes dans la vallée de la Garonne, ainsi qu'autour de certains domaines agricoles (fig. $\mathbf{n}^{\circ} \mathbf{1 6}$ ).

Le bâtiment unique abrite logis, grange, étable, chai et porcherie, et possède une vaste toiture dont les pans descendent à moins de $2 \mathrm{~m}$ du sol. La façade se trouve normalement sous pignon orientée à l'est ou au sud-est, précédée par un auvent ou " balet ", lieu abrité où l'on épluchait le maïs et faisait sécher le tabac. Côté ouest ou nord-ouest, une croupe protège souvent les murs. Le type le plus fréquent dans la vallée de la Garonne est divisé de manière tripartite en longueur : logis d'un côté, grange au centre, étable de l'autre côté. La grange, où sont aussi abritées les charrettes, bénéficie de la plus grande hauteur de toit sous le vaisseau central. 
Figure 15

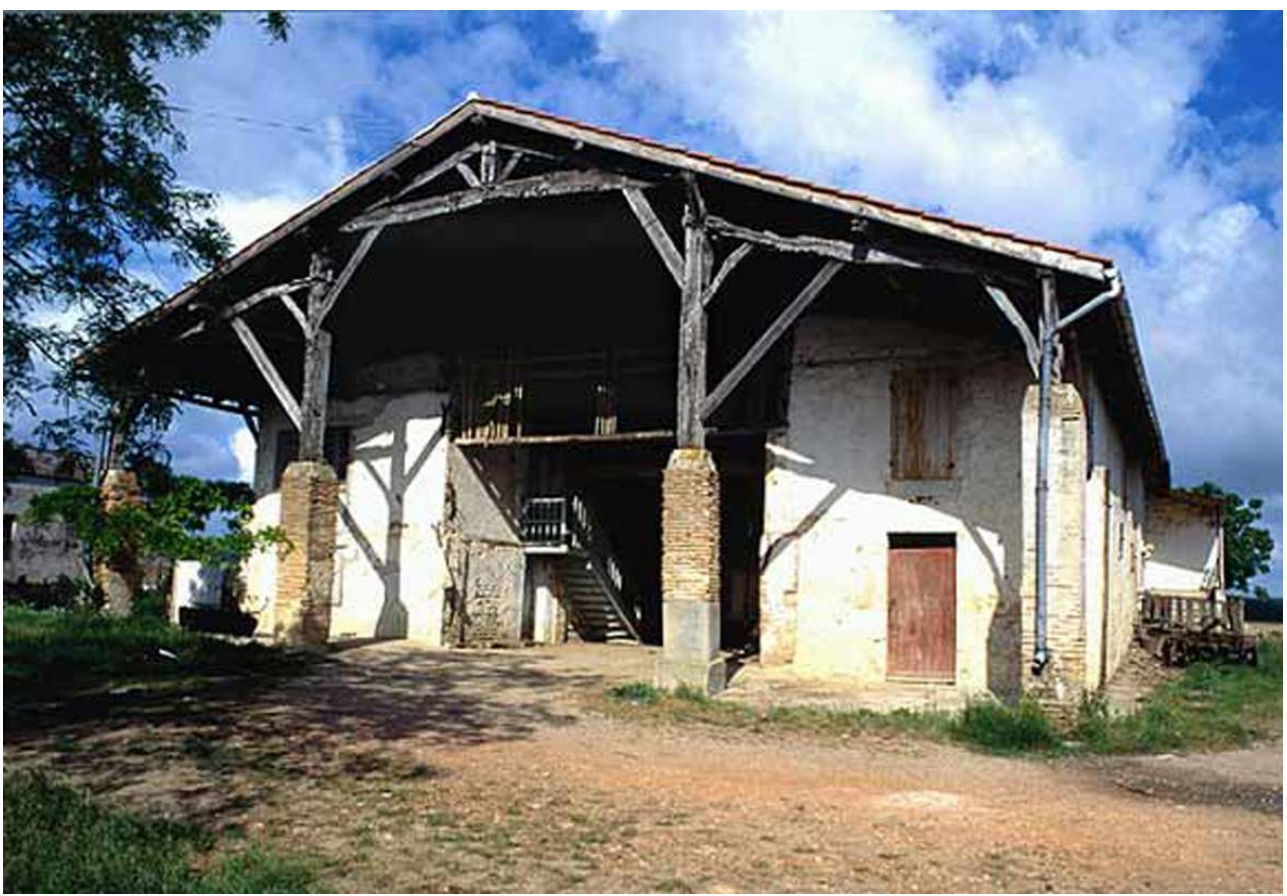

Buzet-sur-Baïse. Barrouil. Ferme : élévation est

Phot. Inv. B. Chabot @ Inventaire général, ADAGP, 1995

Figure 16

Bâtiment isolé abritant sous le même toit logis et dépendances

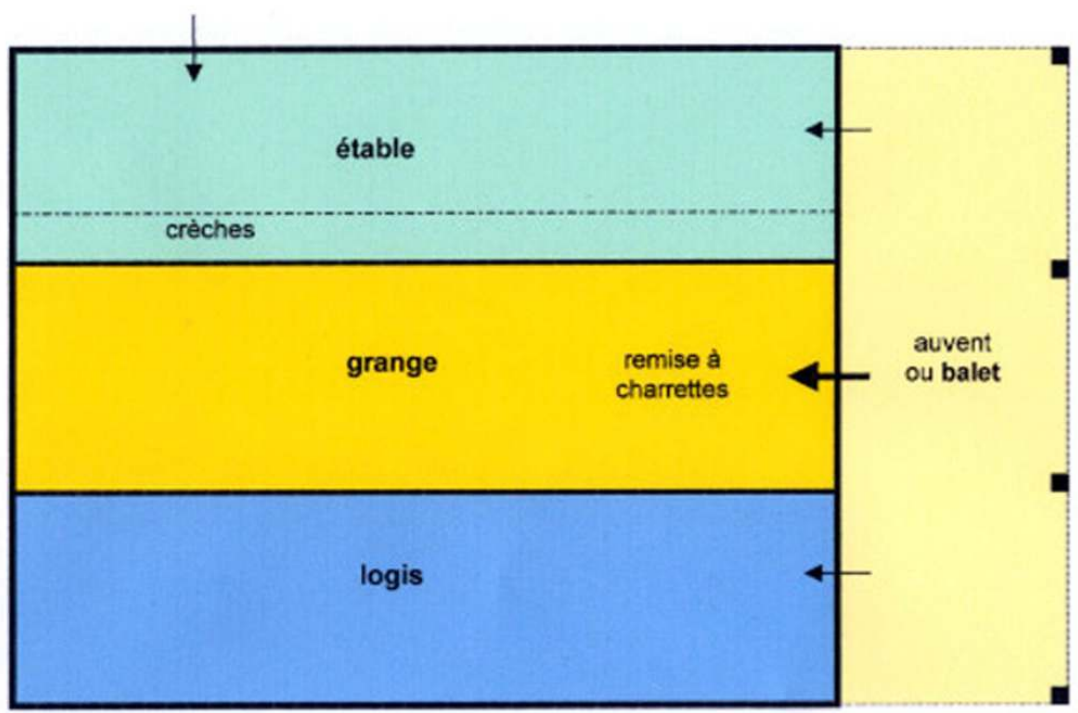

Typologie principale des fermes : bâtiment isolé abritant sous le même toit logis et dépendances Schéma H. Mousset ( I Inventaire général, H. Mousset, 2004 

bâtiments construits d'un seul tenant dans un esprit de logique fonctionnelle et économique étaient souvent - à l'origine - des métairies bâties par un propriétaire terrien. Cela explique que, dans certains domaines agricoles, l'ensemble des métairies corresponde à un modèle unique, conférant à la propriété une unité architecturale et paysagère ${ }^{11}$. maisons de maître ou de notables. Dans ce cas, les bâtiments se déploient autour d'une cour en $U$, dont le logis occupe généralement l'aile du fond : une allée bordée d'arbres, puis la cour et enfin le logis offrent une composition forte dans le paysage, évoquant plus modestement la prégnance des châteaux. Un pigeonnier-porche ou deux pigeonniers carrés aux extrémités des ailes latérales accentuent parfois l'effet d'ensemble (fig. $\mathbf{n}^{\circ} \mathbf{1 8}$ ). Un chai, des écuries et remises, constituent les principaux communs de ces demeures.

\section{Figure 17}

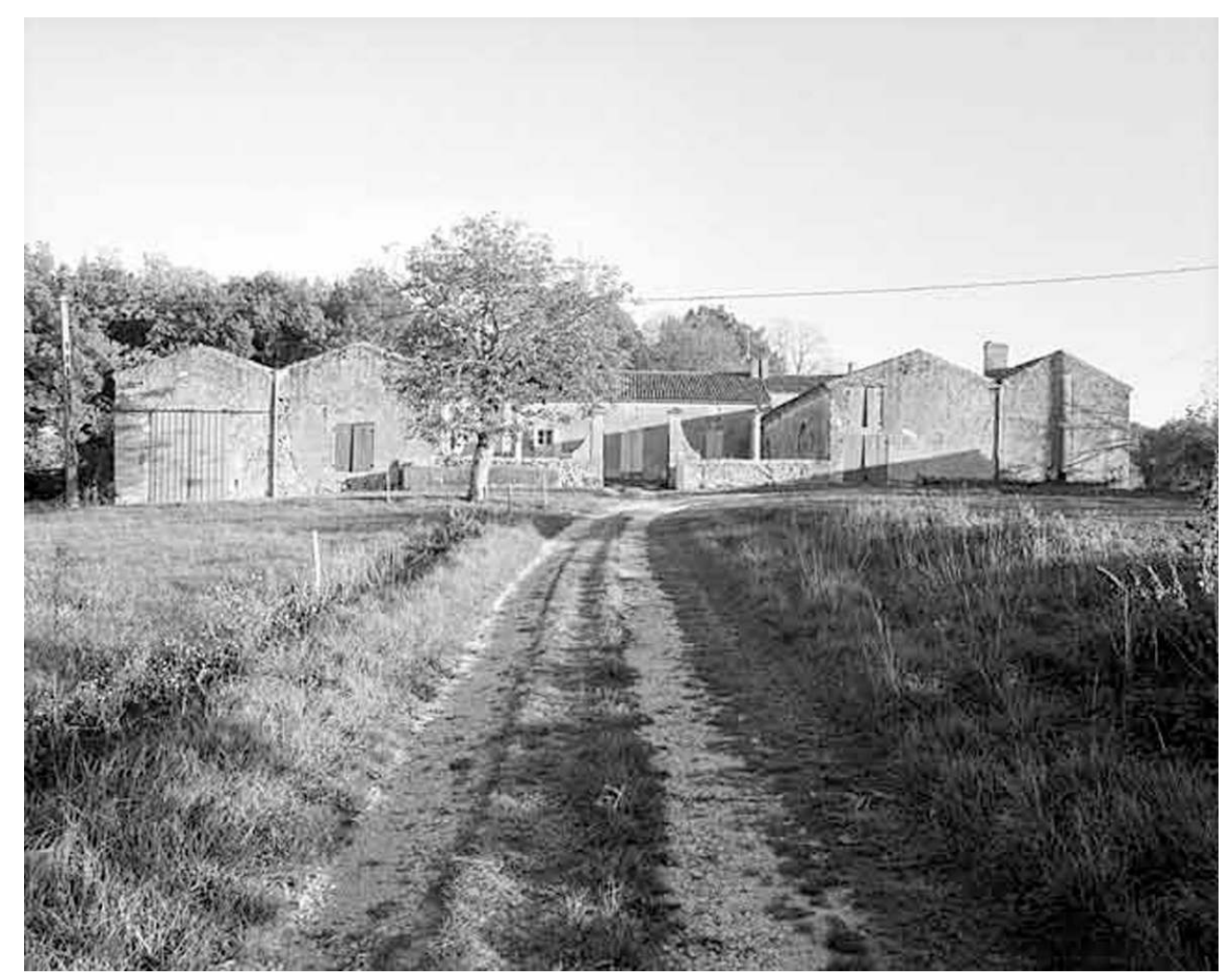

Espiens. La Tuque Neuve. Maison de notable : vue d'ensemble depuis le nord-ouest Phot. Inv. B. Chabot @ Inventaire général, ADAGP, 1995 
Figure 18

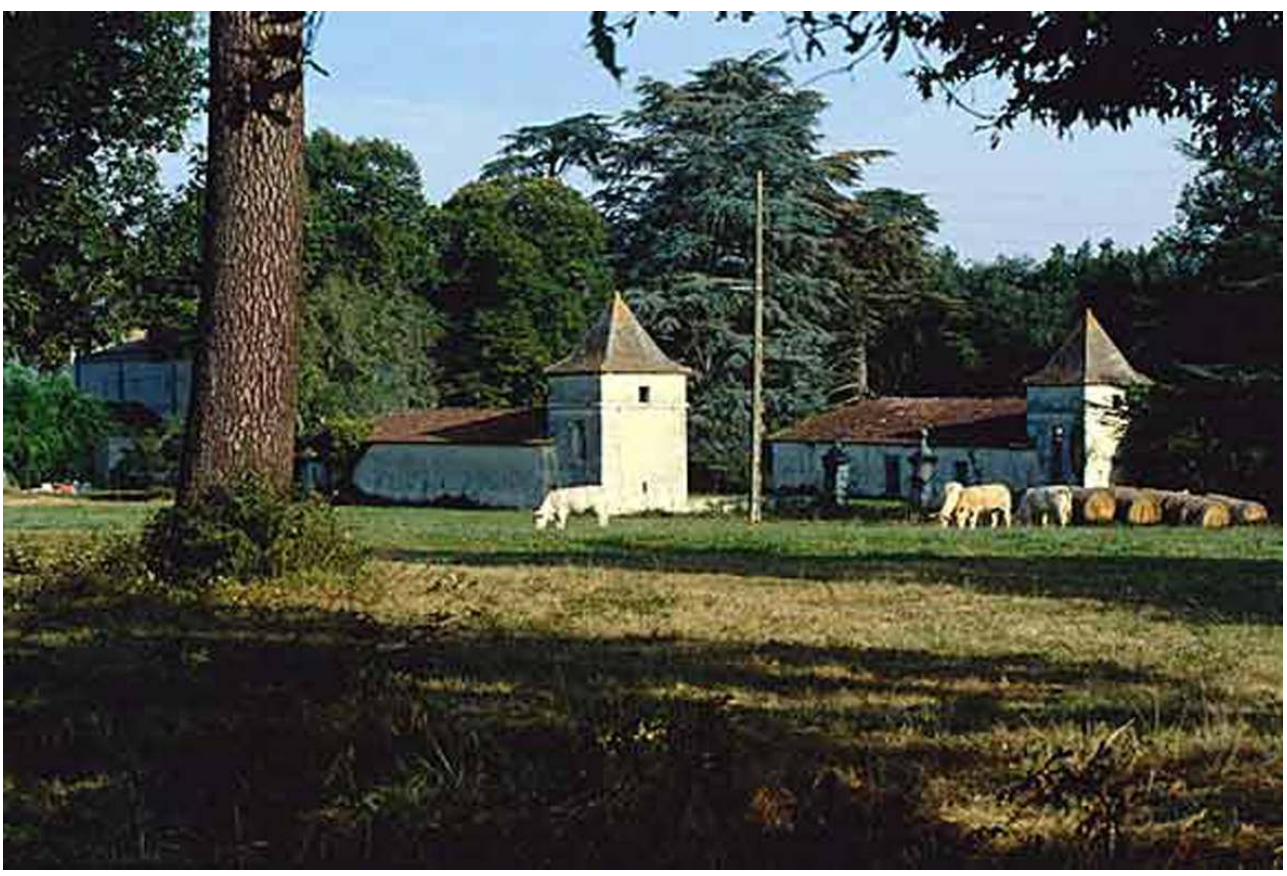

Lamontjoie. Garcin. Maison de maître : vue d'ensemble des dépendances depuis le sud

Phot. Inv. B. Chabot @ Inventaire général, ADAGP, 1997

Ces édifices datent de la fin du XVII ${ }^{e}$ et surtout des XVIII et XIXe siècles.

Les fermes du Fumélois, dont logis et grange-étable rectangulaire forment une équerre, représentent un autre type. Ces bâtiments composés ou recomposés en L (comme d'autres en ligne) semblent dater pour l'essentiel du XIX' siècle.

- Petit logis doté d'une petite grange inclus dans un hameau en ordre lâche (fig. $\mathbf{n}^{\circ}$ 19)

Les hameaux se composaient d'une dizaine à une vingtaine de petits logis, avec une dépendance (grange, étable) (fig. $\mathbf{n}^{\circ} \mathbf{2 0}$ ). Il en subsiste bon nombre dans les Serres et en Fumélois, mais leur conservation est endémique sur les coteaux du sud de la Garonne et dans les Mollasses. 


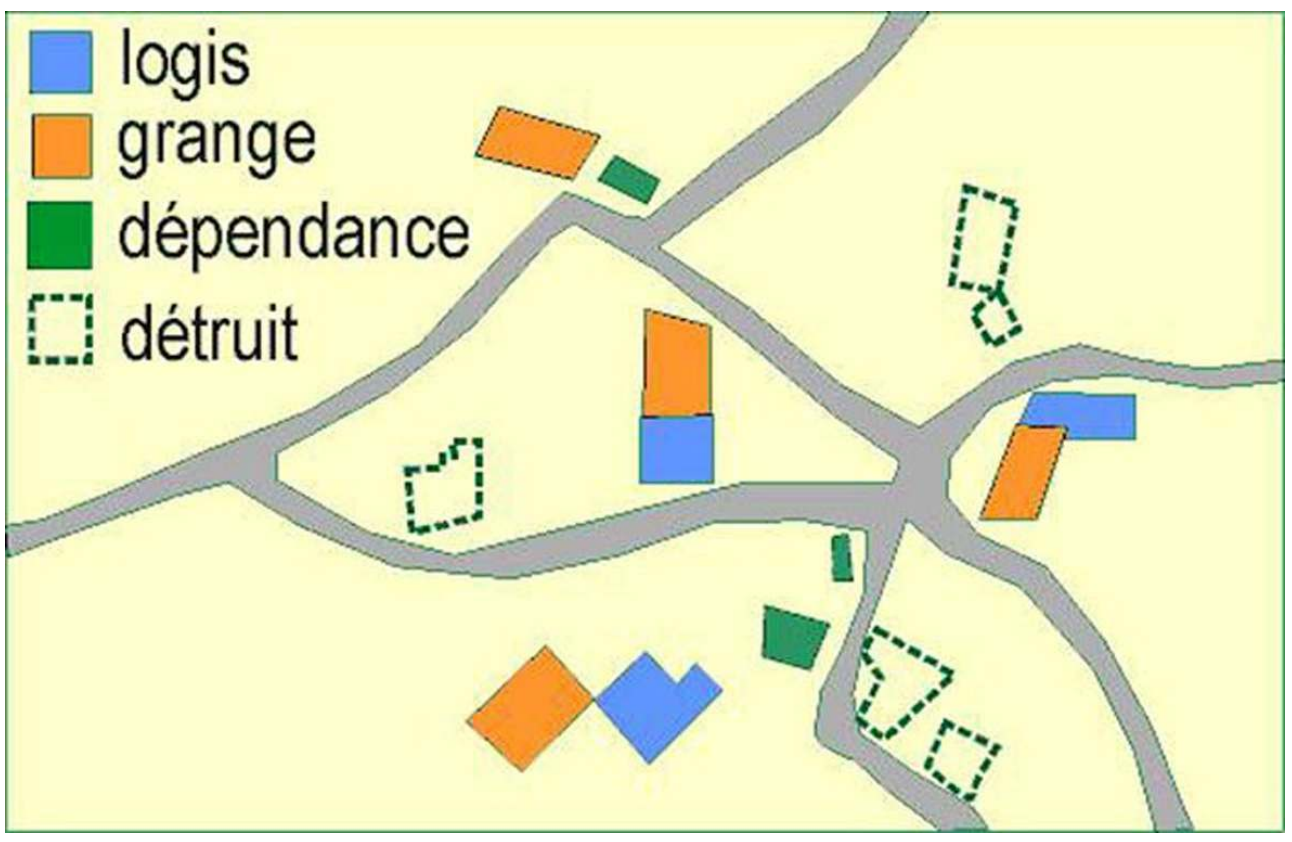

Petits logis dotés d'une grange inclus dans un hameau en ordre lâche

Plan H. Mousset (c) Inventaire général, H. Mousset, 2003

Figure 20

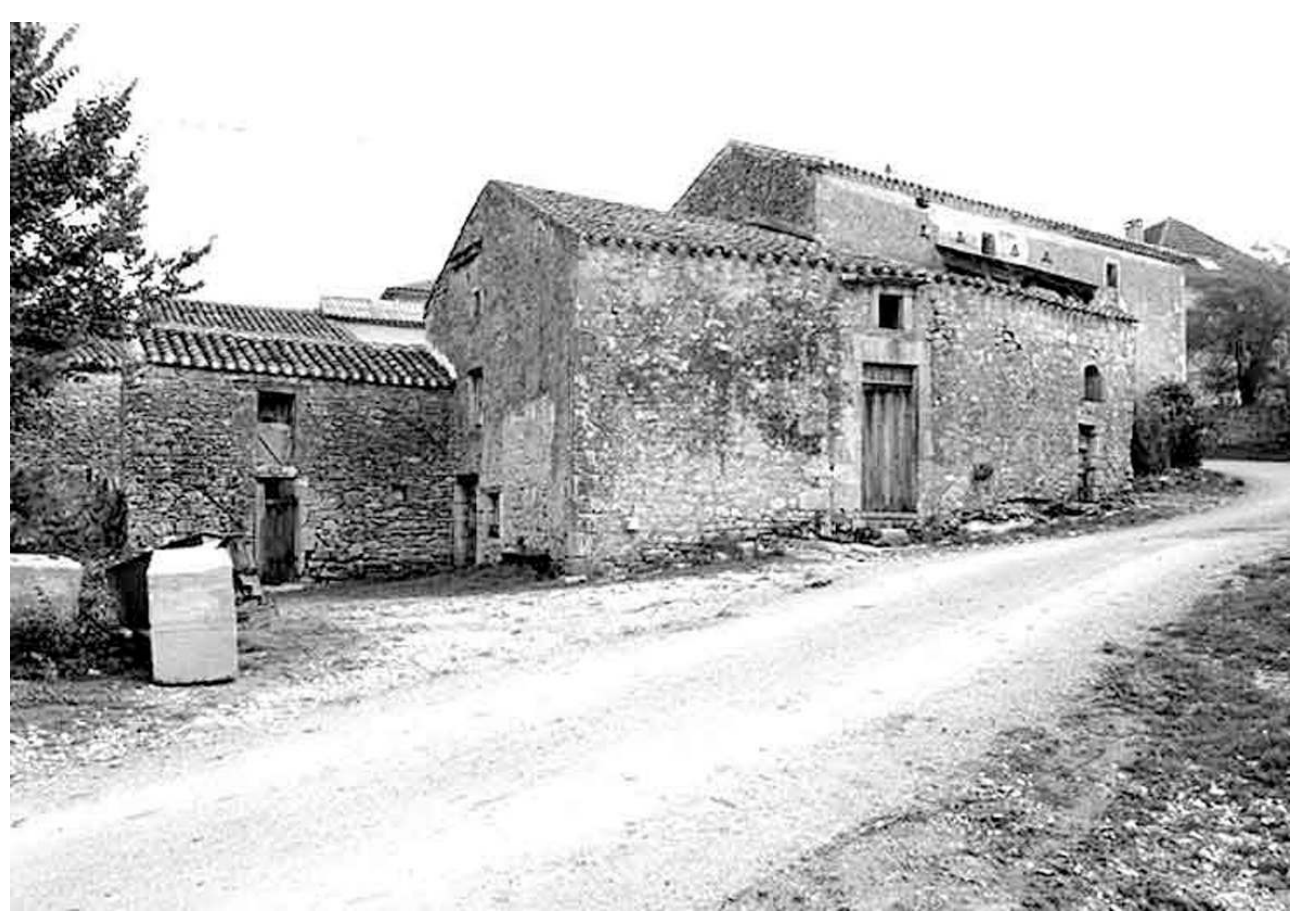

Cuzorn. Laborde. Ferme : vue d'ensemble depuis le sud Phot. Inv. B. Chabot @ Inventaire général, ADAGP, 1996

Les bâtiments sont groupés de manière assez lâche, pour certains agglutinés, pour les autres dispersés. Composés de logis d'une à deux pièces, éventuellement avec cave en soubassement, et d'une grange de petites dimensions, ils témoignent d'un mode de vie 
nécessairement communautaire. Le type de construction indique moins leurs fonctions que leur situation dans le système d'exploitation des ressources par l'homme: hameaux de pêcheurs le long des rivières, de brassiers au sud de la Garonne, de cultivateursouvriers en Fumélois, ou de petits propriétaires au sud de Villeneuve-sur-Lot.

La datation du bâti conservé montre que la construction de cet habitat est prépondérante de la fin du XV ${ }^{e}$ au XVII ${ }^{e}$ siècle, et perdure jusqu'au milieu du XVIII ${ }^{e}$ siècle. Même si les exemples médiévaux sont rarissimes, l'hypothèse d'une pérennité des sites habités et de l'organisation du bâti est en tous cas plausible -surtout dans les Serres où les sources apparaissent déterminantes. Les cartes de Belleyme et de Cassini et les cadastres du début du 19e siècle montrent leur importance. Leur disparition est flagrante entre deux séries de cadastres, ceux des années 1810 et ceux des années 1840, et se prolonge jusqu'en 1930. Comme ils ont été bâtis pour abriter la population nombreuse d'une agriculture réclamant des bras, leur abandon va de pair avec l'exode rural et un changement d'exploitation du sol où l'élevage prend une plus grande part.

Chaque type reflète des habitudes de travail et de vie différentes: présence d'espaces communs dans les hameaux, autarcie de la ferme massée, contrôle des activités dans une cour, confort des logis indépendants... Les bâtiments offrent aussi des volumes qui teintent différemment les paysages: les fermes isolées entourées de leurs terres sur les collines des Mollasses participent à la clarté d'un paysage où exploitations et aménagements se recoupent, tandis que les hameaux qui s'égrènent sur le rebord du plateau des Serres suggèrent un système d'exploitation plus complexe entre plateau, pente et fond de vallée. Dans cette perspective, les bâtiments offrent une approche de la société rurale et des modes d'exploitation.

La manière d'habiter est encore précisée par la forme du logis :

- petits logis d'une ou deux pièces, en rez-de-chaussée, ouvrant par la seule porte, éventuellement une fenêtre. ${ }^{12}$

- maison de trois travées en rez-de-chaussée à façade ordonnancée, comprenant un vestibule et deux ou quatre pièces éclairées par des fenêtres : il s'agit du modèle de très loin le plus courant dans tout le territoire inventorié (fig. $\mathbf{n}^{\circ} \mathbf{2 1}$ ).

- maison à étage : ce sont souvent des maisons de notables ou d'agriculteurs aisés de la seconde moitié $\mathrm{du} \mathrm{XIX}^{\mathrm{e}}$ ou du début du XXe siècle, plus fréquentes dans la vallée du Lot autour de Casseneuil, Sainte-Livrade ou Villeneuve, secteur enrichi par la production de pruneaux ${ }^{13}$.

- habitation à l'étage, au-dessus d'une cave ou d'une écurie (fig. $\mathbf{n}^{\circ}$ 22), accessible par un escalier extérieur en pierre : elle se rencontre essentiellement en Fumélois ou à Tournond'Agenais. 
Figure 21

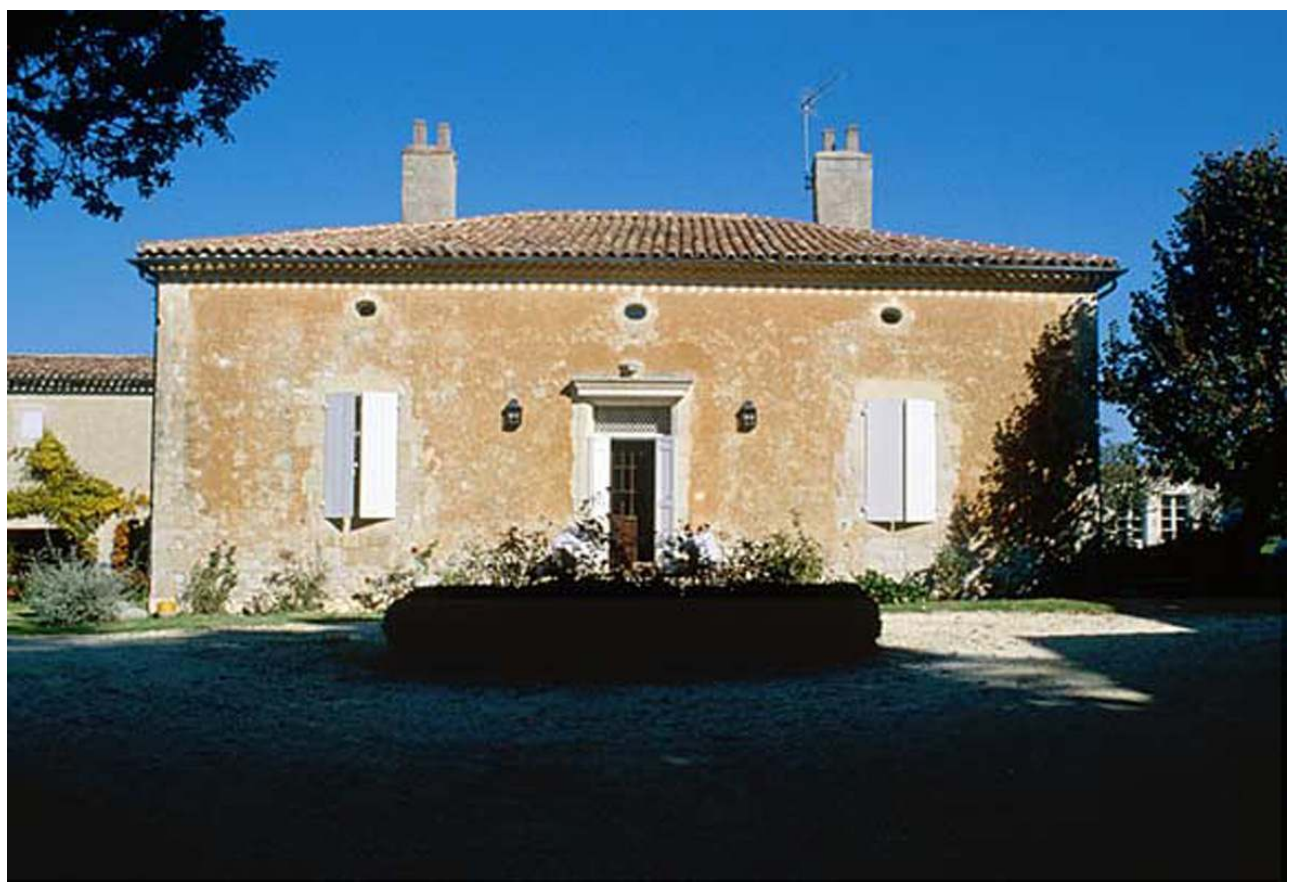

Moncrabeau. Le Mayne. Manoir : ferme du XIXe siècle, dite le Grand Mayne : logis, élévation sud sur cour

Phot. Inv. B. Chabot @ Inventaire général, ADAGP, 1997

Figure 22

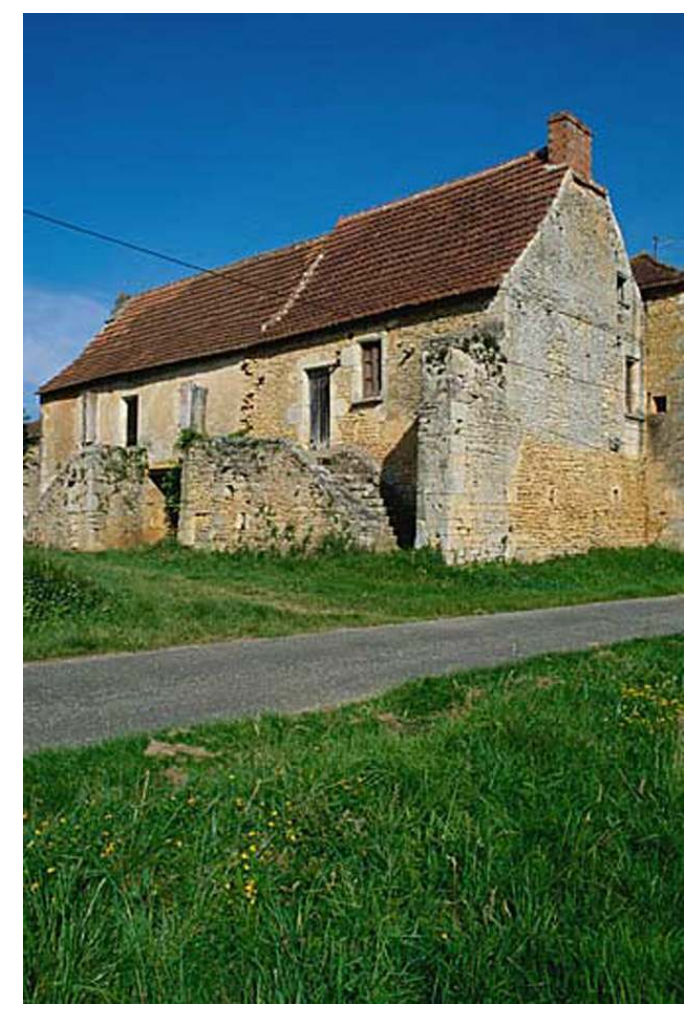

Sauveterre-la-Lémance. Picheyroux. Ferme : vue d'ensemble des logis A et B depuis le sud-est Phot. Inv. B. Chabot @ Inventaire général, ADAGP, 1997 
Figure 23

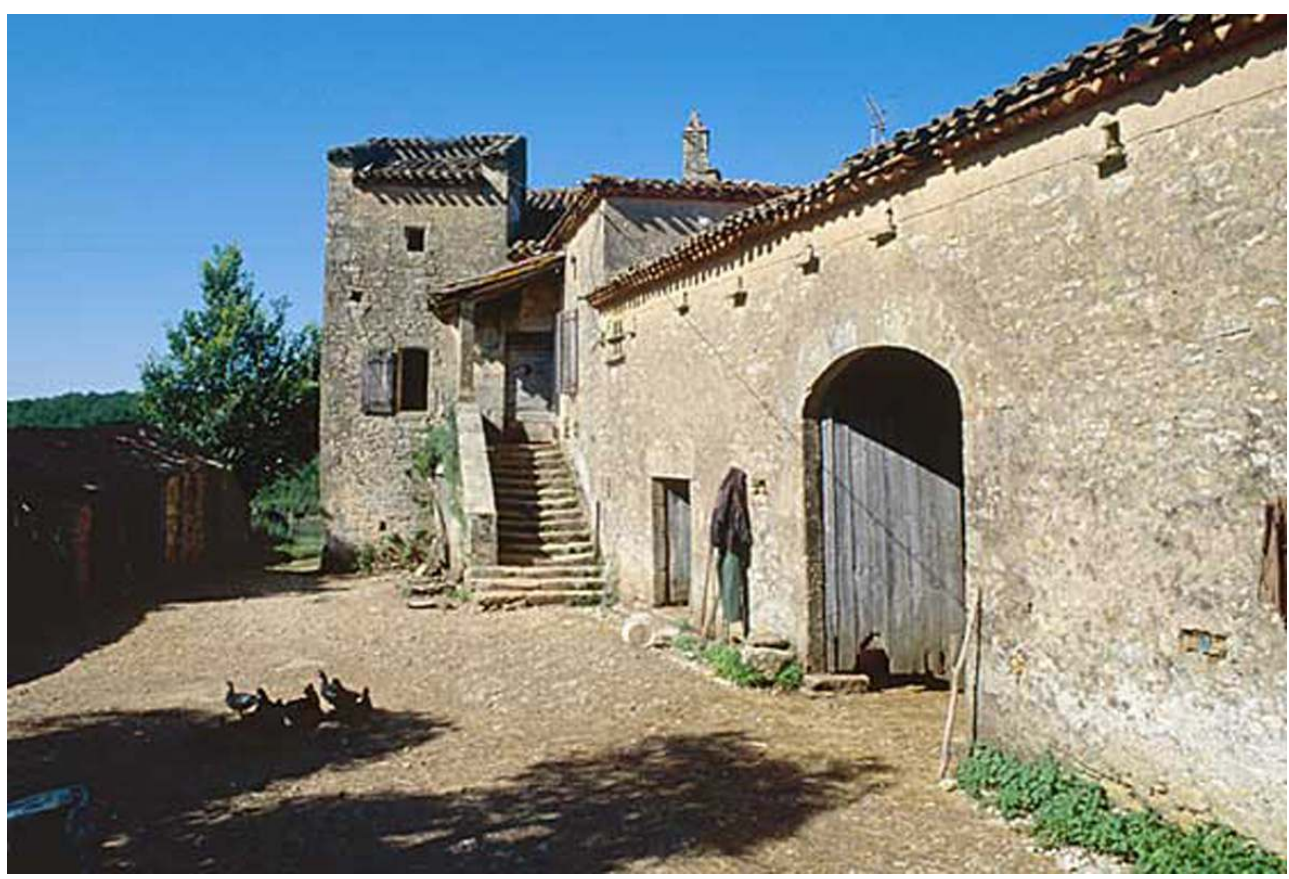

Blanquefort-sur-Briolance. Péchaudral. Ferme : logis et grange-étable vus du sud-ouest

Phot. Inv. B. Chabot @ Inventaire général, ADAGP, 1997

37 Les dépendances agricoles reflètent directement les cultures. Leur nombre et leur variété en Agenais rappellent la polyculture qui a longtemps dominé les systèmes agraires de la région. (fig. $\mathbf{n}^{\circ} \mathbf{2 3}$ ) Une exploitation moyenne comportait des volailles (fig. $\mathbf{n}^{\circ}$ 23) et porcs, quatre ou cinq bœufs et vaches de labour, les semences (la " pile"), souvent quelques moutons et enfin des barriques de vin : d'où la porcherie, le poulailler, l'étable avec fenil et la grange, le garde-pile, la bergerie, une cave, enfin un puits et un four à pain. D'autres dépendances paraissent moins systématiques, liées à un secteur ou à un statut de propriété : pigeonnier, four à prunes, grand chai à cuves et pressoir ou séchoir à tabac. Certaines parties agricoles témoignent d'une relative spécialisation et présentent leur propre diversité architecturale: pigeonniers, granges-étables, fours à prunes ou séchoirs à tabac.

\section{Pigeonniers}

La construction d'un pigeonnier est le signe d'une certaine aisance, mais aussi une ressource pour l'alimentation et l'apport de colombine nécessaire aux cultures. Les pigeonniers circulaires ou colombiers avec trous de boulins de fond en comble appartiennent toujours à une maison noble. Les autres types dépendent de maisons de notables ou de fermes. La répartition géographique est partagée pour certains types : le pigeonnier en appentis ou pied-de-mulet, si fréquent dans la région toulousaine, ne se rencontre ici que dans la partie est.

Huit formes de pigeonniers ont été identifiées : 


\section{Figure 24}

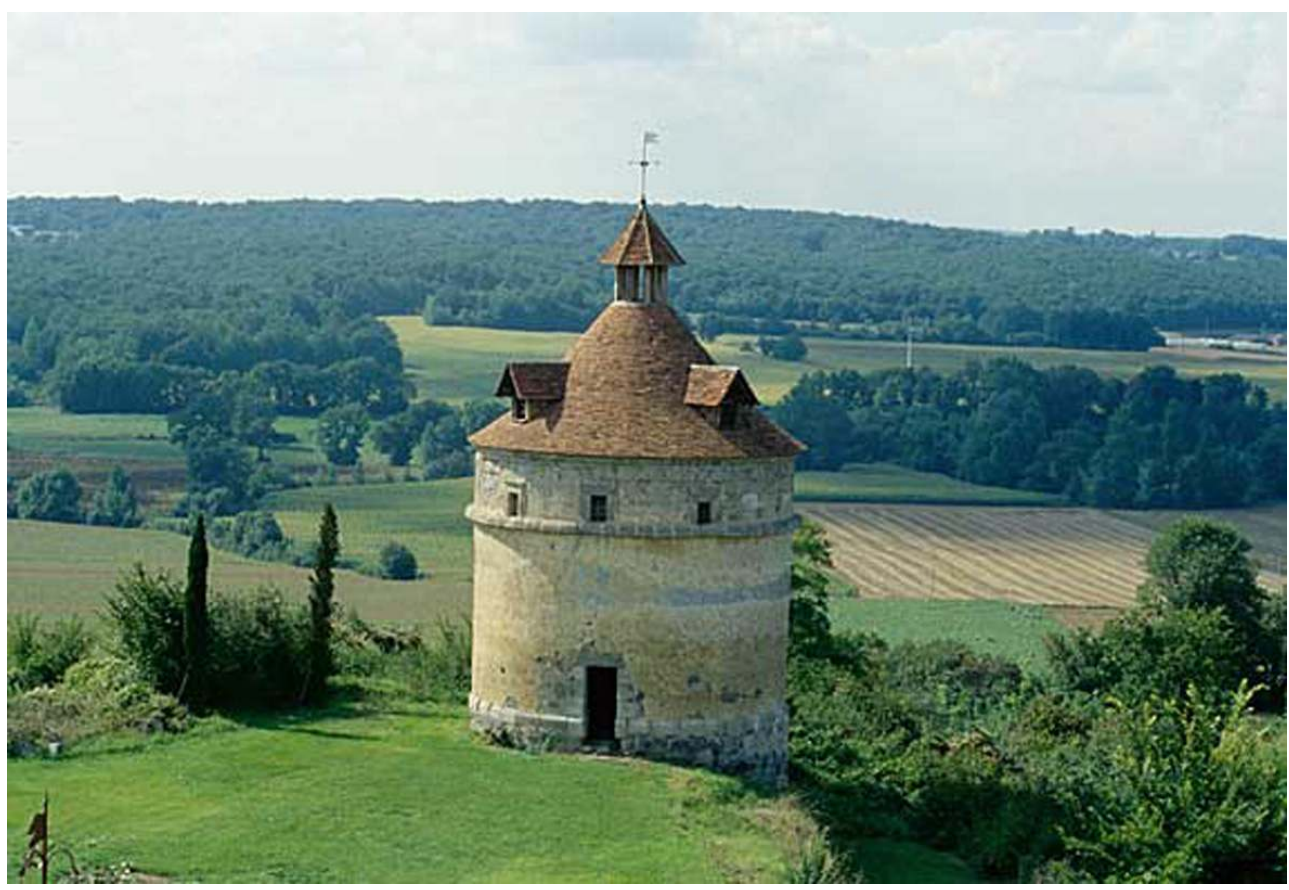

Fréchou. Château Colombier : vue prise du château

Phot. Inv. B. Chabot @ Inventaire général, ADAGP, 1996

\section{Figure 25}

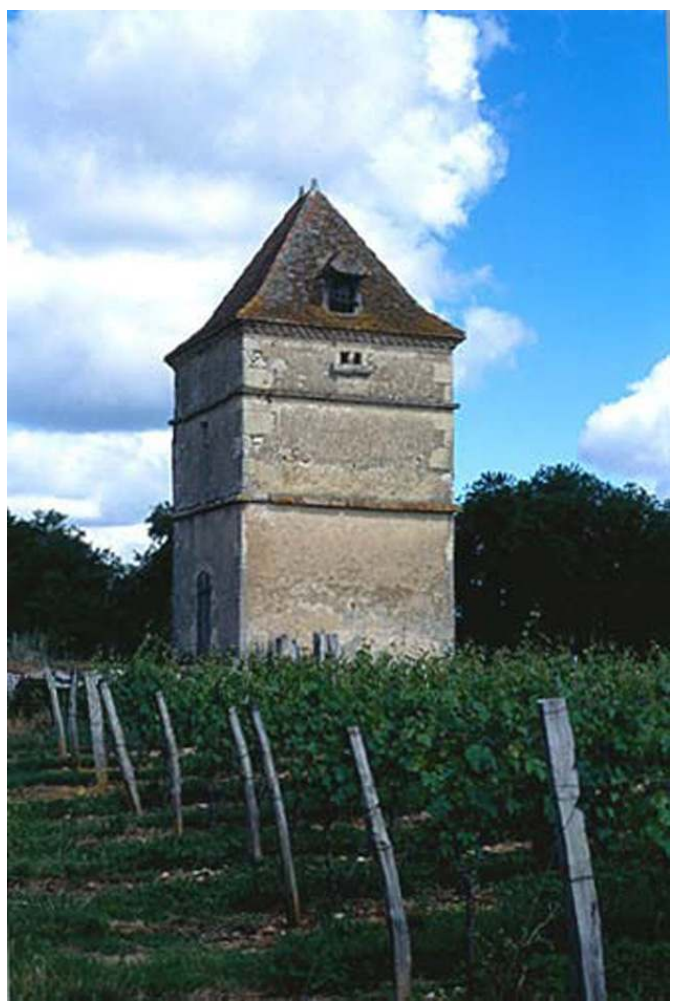

Xaintrailles. Doumerc. Ferme : pigeonnier

Phot. Inv. B. Chabot @ Inventaire général, ADAGP, 1995 


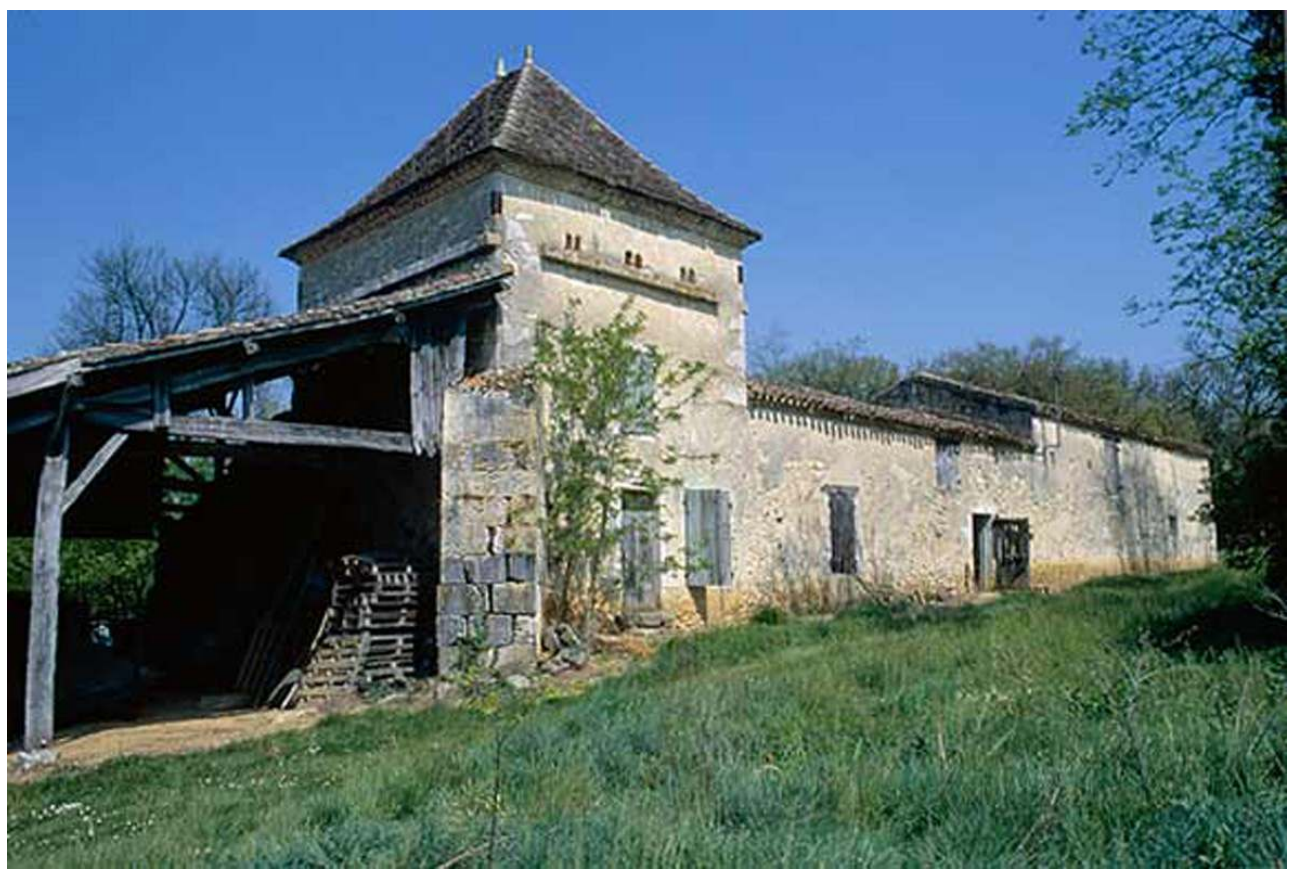

Lavardac. Bourdiol. Ferme : élévation sud

Phot. Inv. B. Chabot @ Inventaire général, ADAGP, 1995

Figure 27

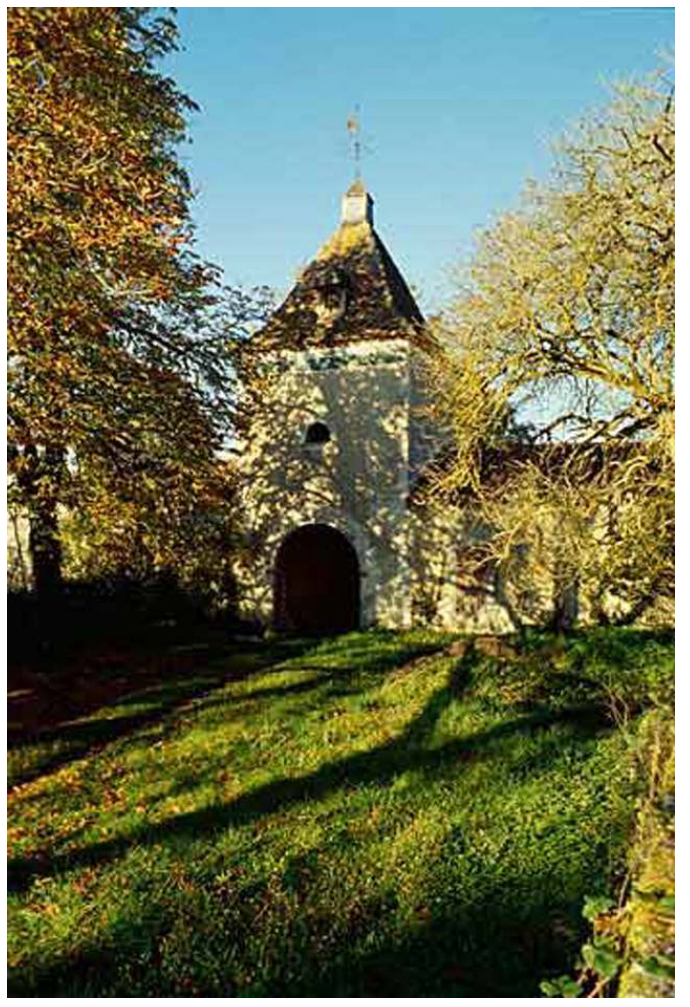

Espiens. Rose Heyte. Château : pigeonnier, élévation est

Phot. Inv. B. Chabot @ Inventaire général, ADAGP, 1995 
Figure 28

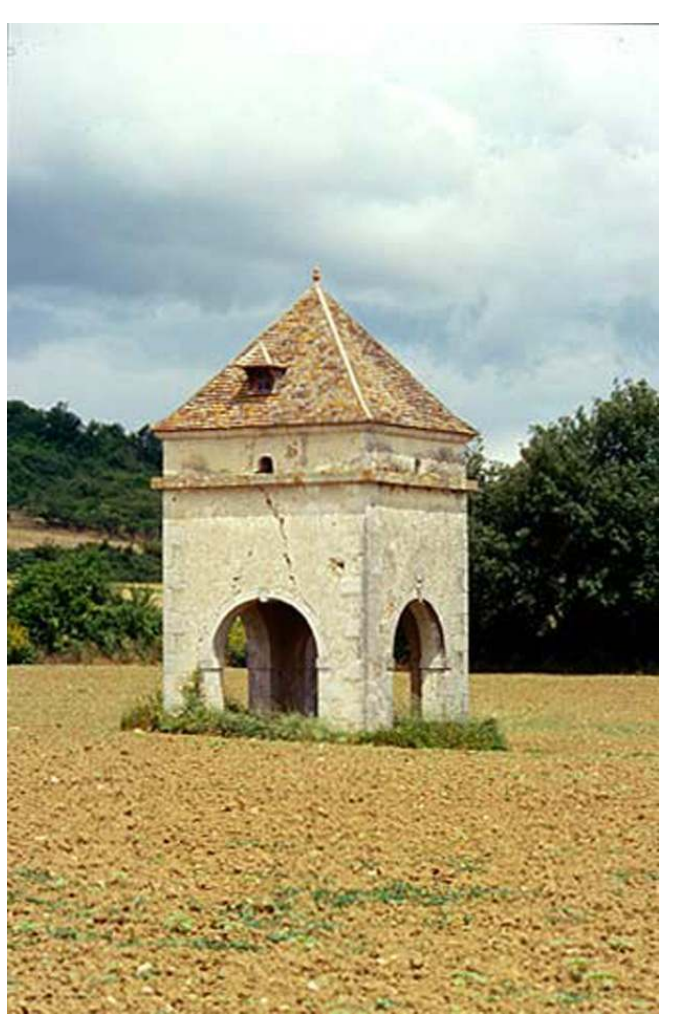

Nérac. Gaujac. Pigeonnier : élévations ouest et sud

Phot. Inv. B. Chabot @ Inventaire général. AGAGP. 1995 
Figure 29

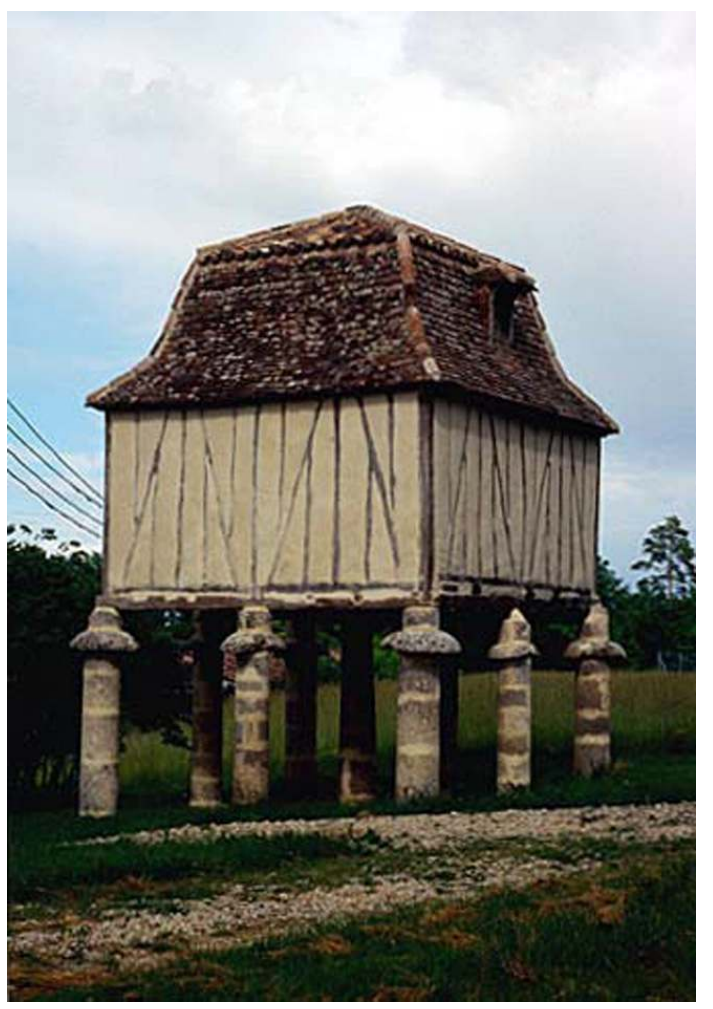

Mézin. Carboste. Château : pigeonnier

Phot. Inv. B. Chabot @ Inventaire général, ADAGP, 1995 
Figure 30

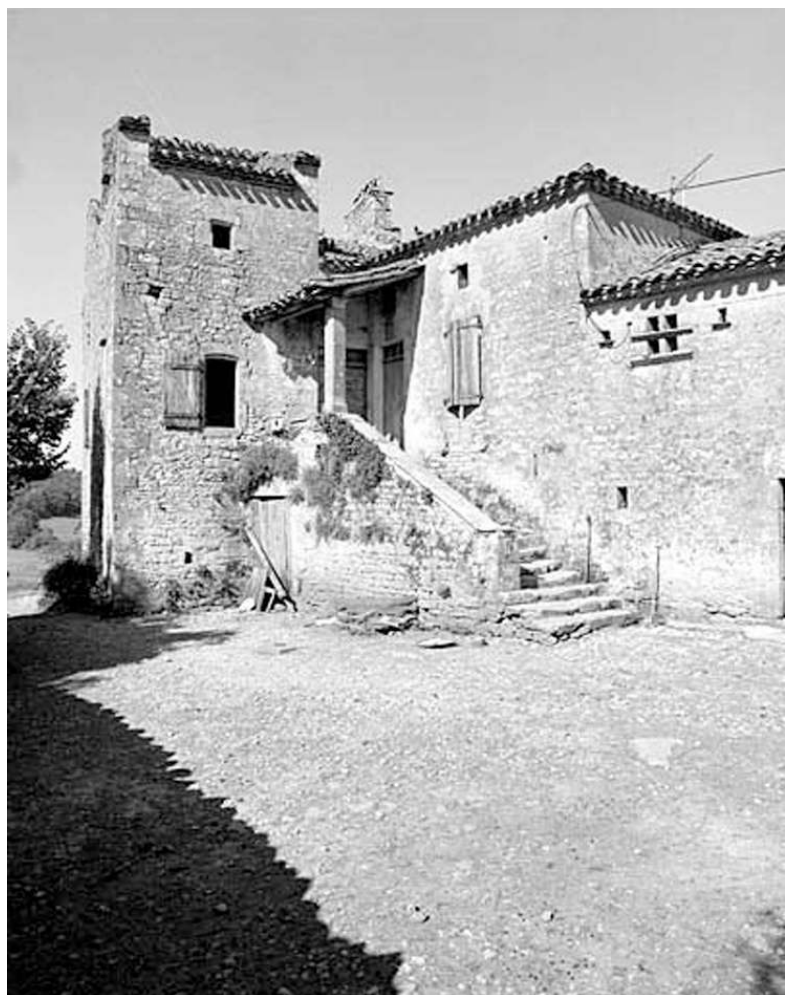

Blanquefort-sur-Briolance. Péchaudral. Ferme : logis vu du sud-ouest Phot. Inv. B. Chabot @ Inventaire général, ADAGP, 1997

Deux principaux types ont été identifiés :

\section{Fours à prunes ou étuves}


Figure 31

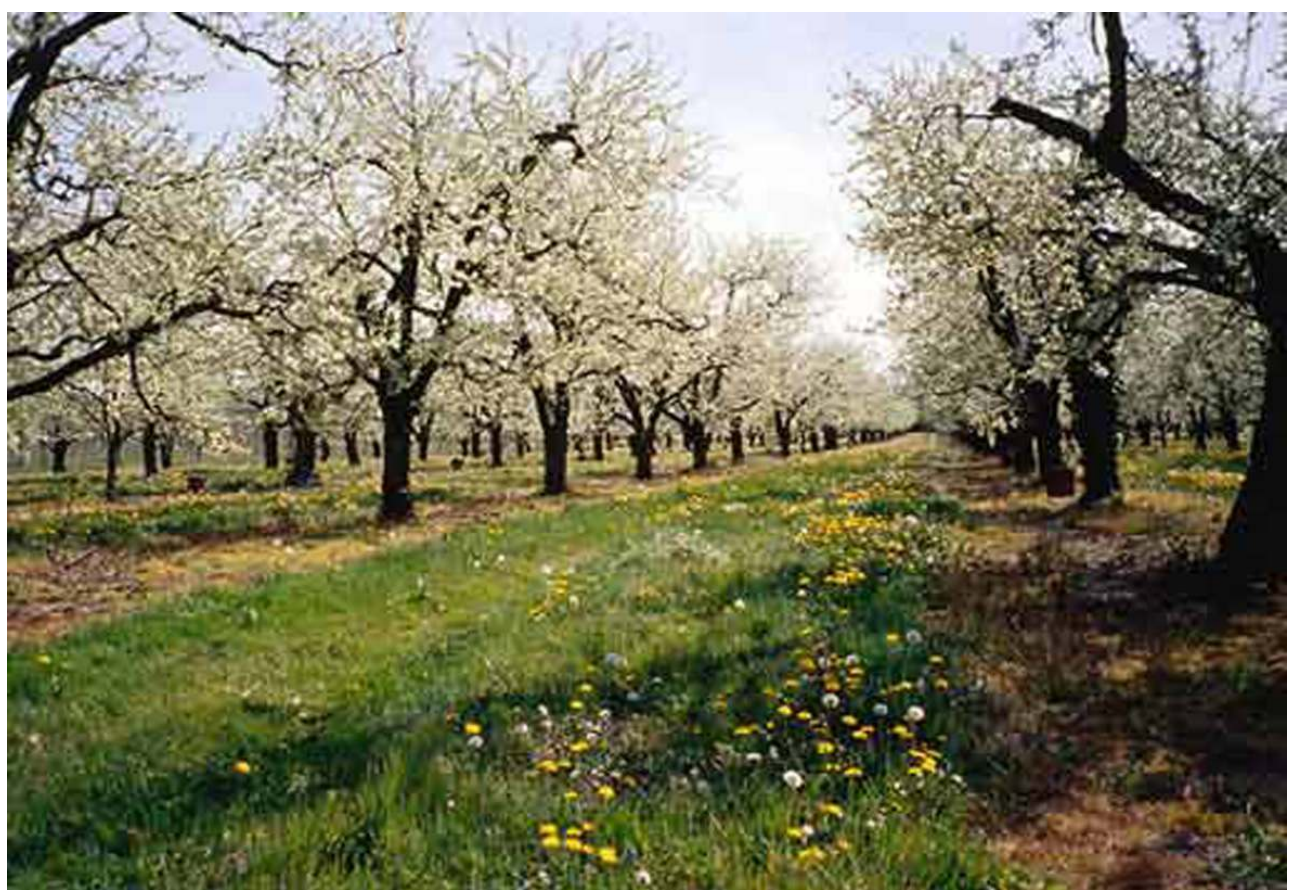

Port-Sainte-Marie. Bourran. Paysage : vergers près de Colleignes

Phot. Inv. H. Mousset @ Inventaire général, ADAGP, 2000

Les conditions de l'enquêteGranges-établesLa culture des prunes (fig. $n^{\circ}$ 31) est pratiquée depuis le Moyen Age. Leur transformation en pruneaux par "étuvage" dans un four permettait leur exportation vers les ports de l'Atlantique : la consommation des pruneaux embarqués sur les bateaux aidait à lutter contre le scorbut.

\section{Séchoirs à tabac}

La culture du tabac est autorisée dans la vallée de la Garonne dès le XVII ${ }^{e}$ siècle. Les feuilles étaient mises à sécher sous le balet des fermes. Des bâtiments en bois, puis en brique creuse et zinc, n'ont été édifiés qu'au XX $\mathrm{XX}^{\mathrm{e}}$ siècle (fig. $\mathbf{n}^{\circ}$ 33).

La progression géographique des enquêteurs a fait apparaître des éléments nouveaux, bergeries en équerre des landes (fig. $\mathbf{n}^{\circ}$ 34) ou fermes en pisé du Villeneuvois ${ }^{14}$. 
Figure 32

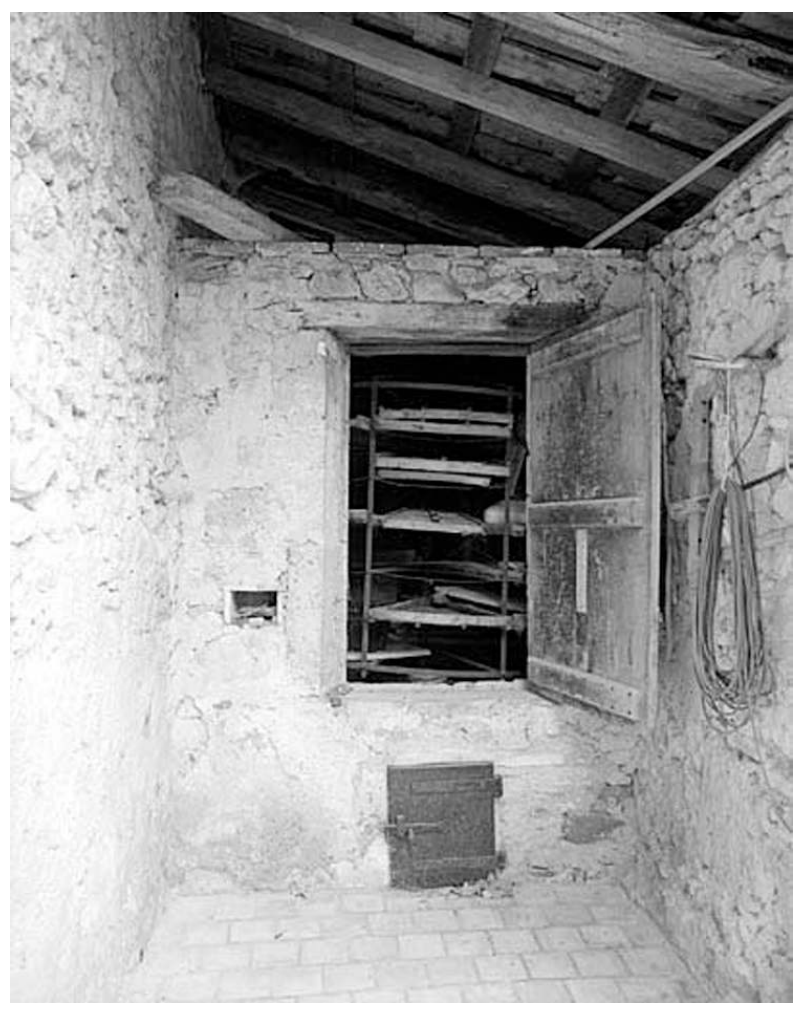

Bazens. Le Vivet. Maison de maître : four à prunes

Phot. Inv. M. Dubau @ Inventaire général, ADAGP, 1998

Figure 33

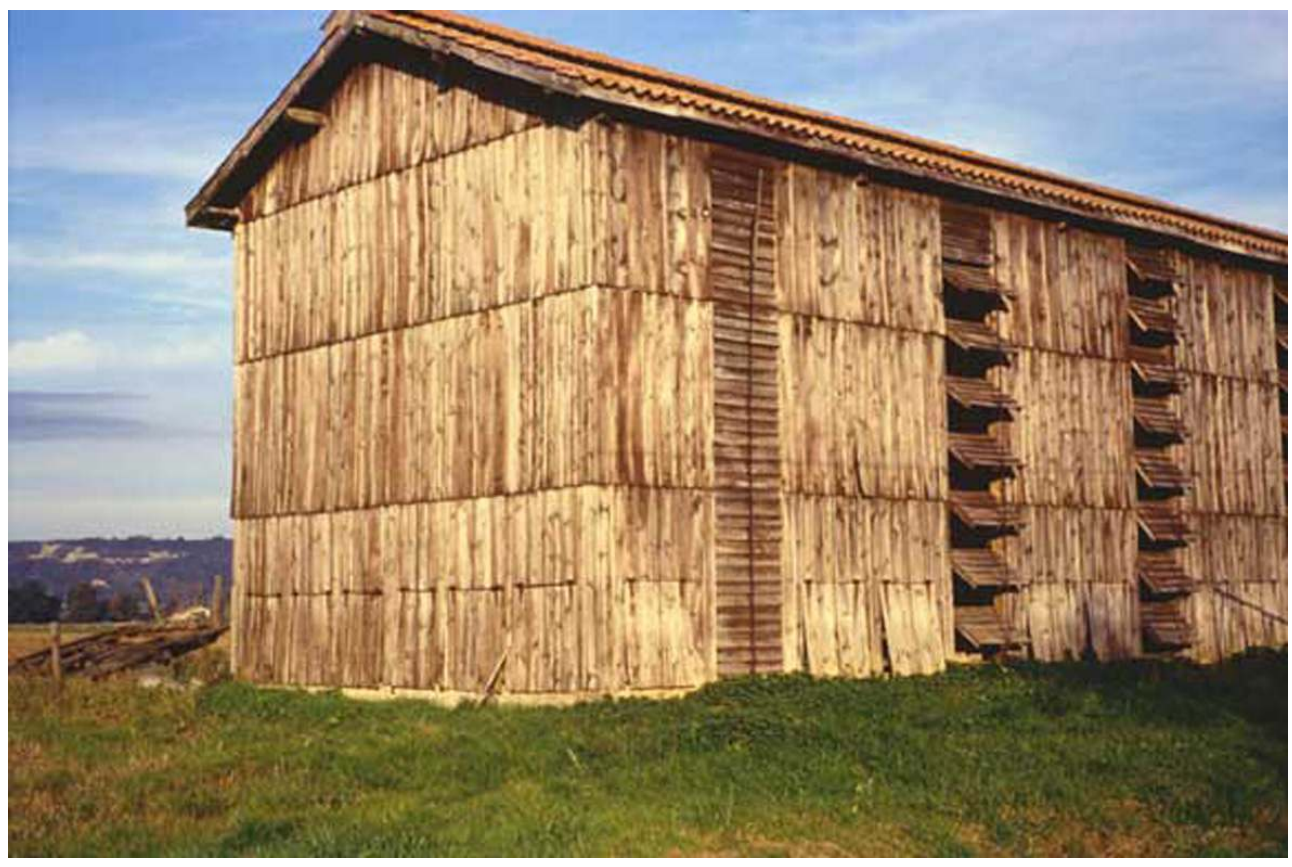

Damazan. Sotte. Séchoir à tabac : vue d'ensemble

Phot. Inv. H. Mousset (C) Inventaire général, ADAGP, 2000 
Figure 34

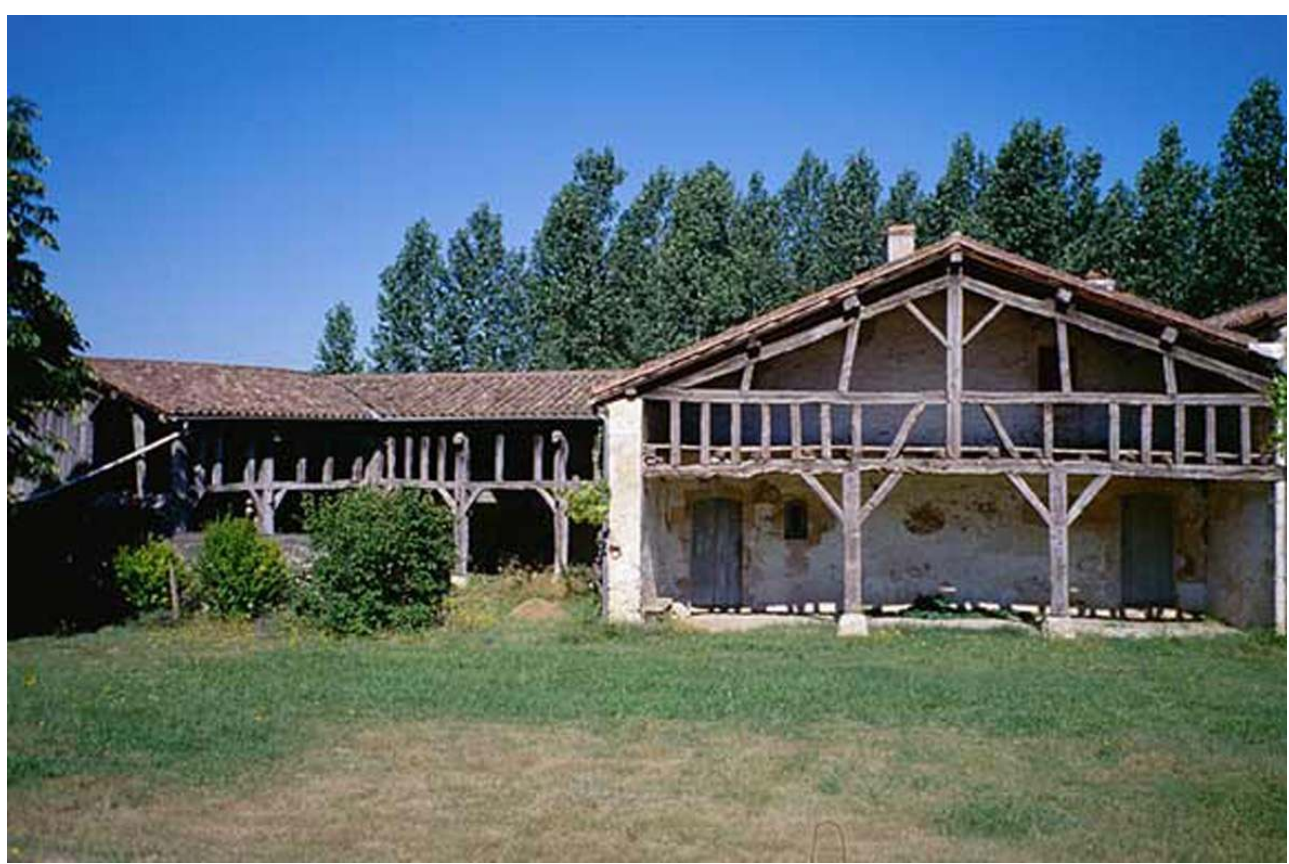

Sos. Péroc. Ferme : vue des logis et des étables depuis l'est

Phot. Inv. H. Mousset (C) Inventaire général, ADAGP, 1998

\section{L'intérêt des exceptions}

La typologie met immédiatement en exergue les édifices exceptionnels, qui sont considérés avec une attention particulière. Ils peuvent en effet être représentatifs d'une disposition jadis fréquente et qui a majoritairement disparu, d'une manière de bâtir micro-locale ou encore d'une transition entre deux modes de construction ${ }^{15}$. Ne pouvant énumérer tous ces cas et les questions qu'ils posent, nous nous contenterons de quelques exemples de bâti peu courants pour en suggérer l'intérêt. 


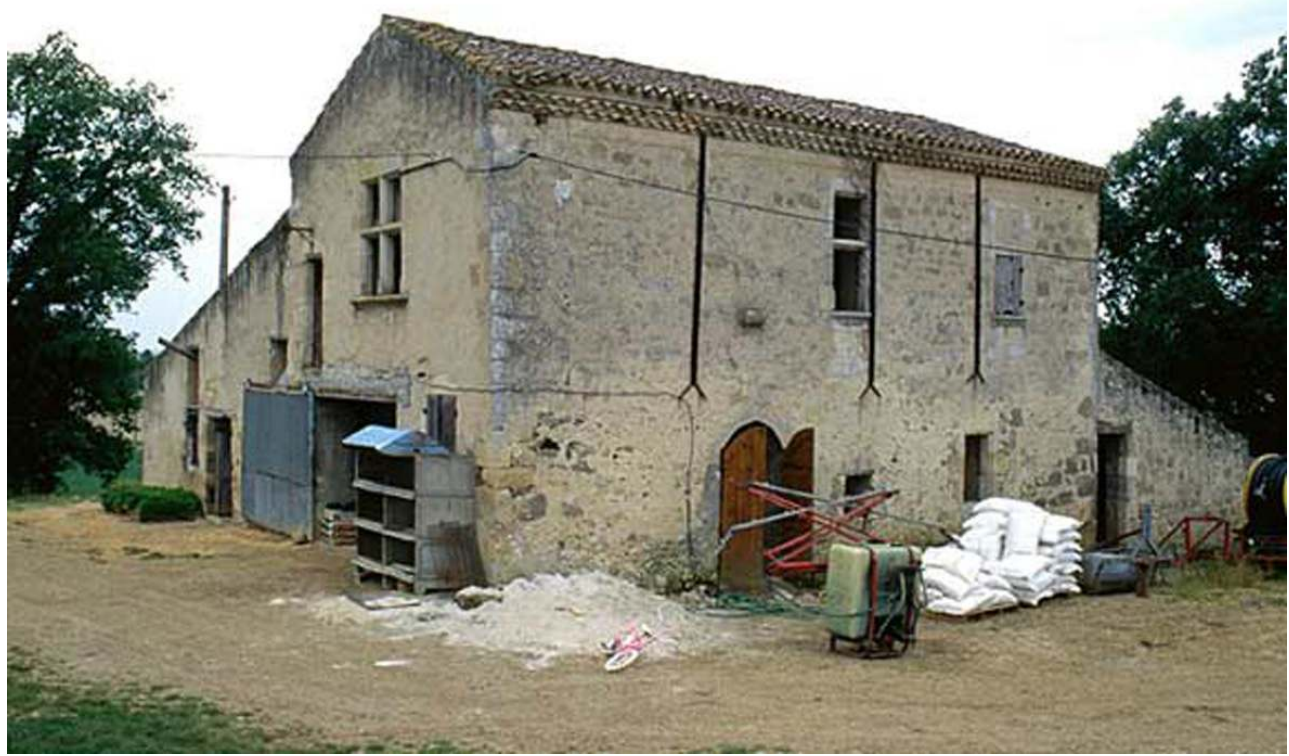

Moncrabeau. Lespeau. Ferme : vue d'ensemble depuis le nord-est

Phot. Inv. B. Chabot @ Inventaire général, ADAGP, 1995

Un petit groupe de demeures du tournant des $\mathrm{XV}^{\mathrm{e}}$ et $\mathrm{XVI}^{\mathrm{e}}$ siècles disposent de l'habitation à l'étage sans escalier extérieur en maçonnerie (fig. $\mathbf{n}^{\circ} \mathbf{3 5}$ ). Comme dans les maisonsfortes, le rez-de-chaussée servait sans doute au stockage et aux bêtes. Ces exemples posent des questions pour l'instant sans réponse : est-ce le souvenir d'une distribution médiévale jadis commune? ou s'agit-il de maisons de la petite noblesse, bâties à l'imitation des maisons-fortes?

Hormis pour la couverture des pigeonniers, la tuile plate n'est pas couramment employée dans la région, mais apparait pourtant sur des demeures du XVI siècle dans la vallée de la Baïse ou des $\mathrm{XVI}^{\mathrm{e}}$ et $\mathrm{XVII}{ }^{\mathrm{e}}$ siècles au nord du Lot. Vestiges d'une mode passagère ? Plus pérenne au nord du département comme elle l'est en Dordogne?

47 La construction en empilage de poutres suppose des bois longs de haute futaie (déterminant la longueur de la maison) et repose sur une technique inconnue dans le reste du Sud-Ouest. Certains y ont vu le bâti d'un pays de bois au nord du Lot-et-Garonne et au sud de la Dordogne. Les découvertes de l'inventaire loin du secteur connu montrent que ce mode de construction était plus répandu qu'on ne le pensait et relancent les hypothèses.

La terre fut un matériau important de nos campagnes (torchis en hourdis du pan de bois ou même pisé), mais elle est aujourd'hui résiduelle et minorée. Autour de Sainte-Livrade, Villeneuve et Saint-Sylvestre, on trouve nombre de fermes ou de granges en pisé montées par strates de $80 \mathrm{~cm}$ environ selon la technique du banchage. Elles ont été édifiées à la fin du XVIII et dans la première moitié du XIX ${ }^{e}$ siècle, période de construction intensive. 


\section{L'espace rural dans son ensemble}

\section{Prise en compte des diverses composantes de l'espace rural}

Les fermes constituent la majeure partie du bâti de l'espace rural, mais d'autres éléments forts s'imposent dans le paysage : bourg, église, tête de domaines, pont, moulin à eau et à vent...

Figure 36

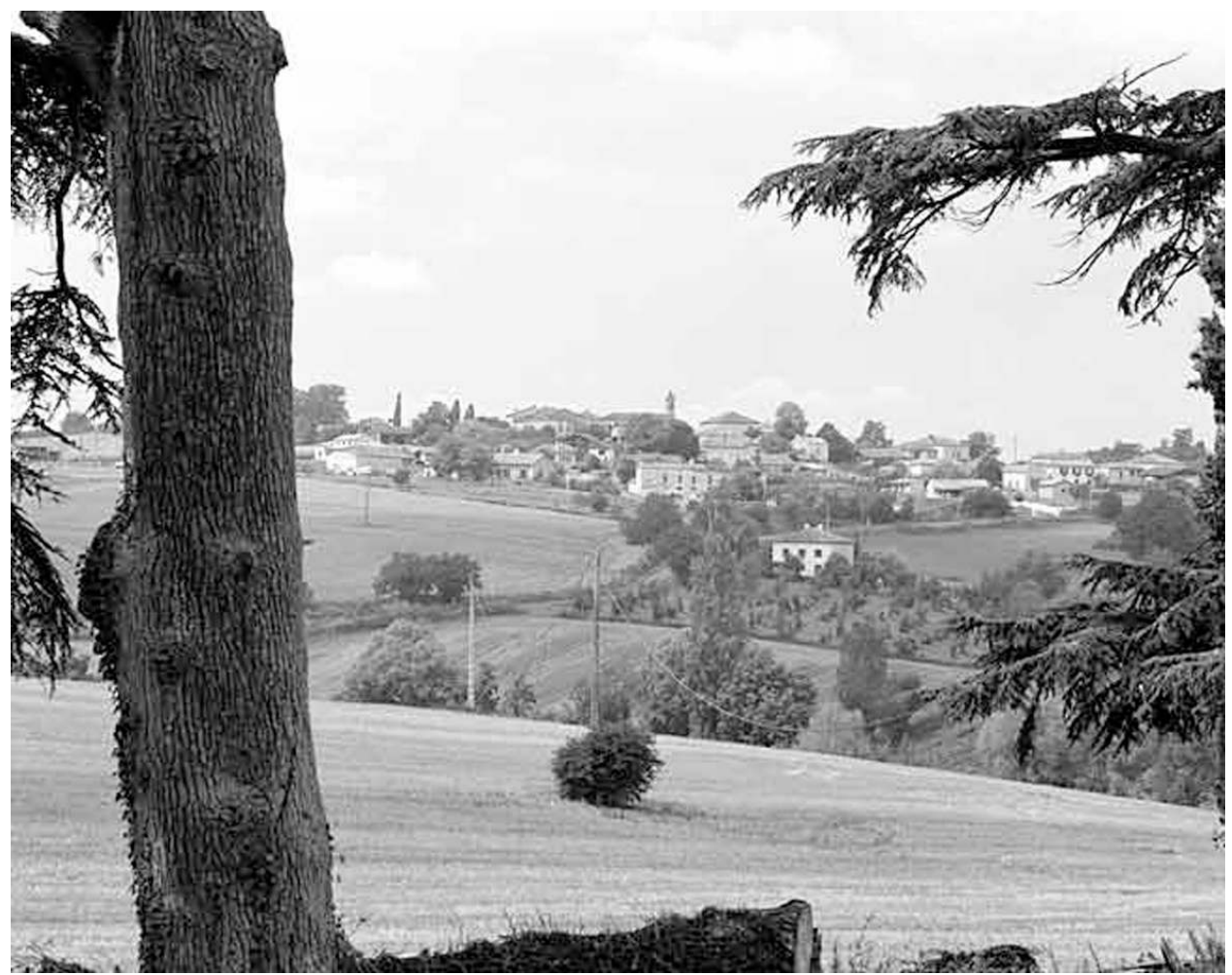

Calignac. Village. Vue d'ensemble depuis le sud-est

Phot. Inv. B. Chabot @ Inventaire général, ADAGP. 1996

L'espace rural est organisé par le réseau des bourgs formé dès le Moyen Age (fig. $\mathbf{n}^{\circ}$ 36), avec des rôles de marchés et de refuges (fig. $n^{\circ} 36$ ) Tous étaient fortifiés sur un site choisi pour ses possibilités défensives - mais souvent contraignant pour le développement de l'agglomération. En Albret, le réseau des villages est très régulièrement organisé, au point de rappeler les théories de Christaller, mais une concentration le long de la Baïse démontre l'attrait de la rivière. Autour du Lot, les bourgs ecclésiaux et castraux en place aux $\mathrm{XI}^{\mathrm{e}}-\mathrm{XII}^{\mathrm{e}}$ siècles ont été complétés par les bastides des $\mathrm{XIII}^{\mathrm{e}}-\mathrm{XIV}^{\mathrm{e}}$ siècles, notamment Villeneuve-sur-Lot.

51 L'église était l'édifice central de la paroisse, cadre humain fondamental du Moyen Age et de l'Ancien Régime. De nouvelles églises annexes desservaient les nouvelles populations, en particulier celle des villages ou bastides, et, au XIIIe siècle, leur densité devient un signe de l'importance du peuplement : le contraste est net entre les landes et le confluent du Lot et de la Garonne. 
Les villages et les églises ne sont pas seuls à concourir à la compréhension de l'espace : tous les éléments se complètent et s'articulent entre eux (fig. $n^{\circ}$ 37).

53 Au sud de la Garonne aux XVII ${ }^{e}$ et XVIII ${ }^{e}$ siècles, par exemple, le système agraire se fondait sur trois éléments visibles dans l'architecture : la riche demeure du propriétaire terrien (château ou manoir), des métairies isolées alentour, parfois construites sur un même modèle (fig. $\mathbf{n}^{\circ} \mathbf{3 8}$ ), et des hameaux de brassiers fournissant une main-d'œuvre pour certains travaux.

54 Le système économique était complété par les grands moulins sur la Baïse et la Gélise (fig. n 39), ainsi que les chemins, comme la Ténarèze, et les voies navigables, permettant l'exportation des farines, vins et eaux-de-vie vers les Antilles par le port de Bordeaux.

Figure 37

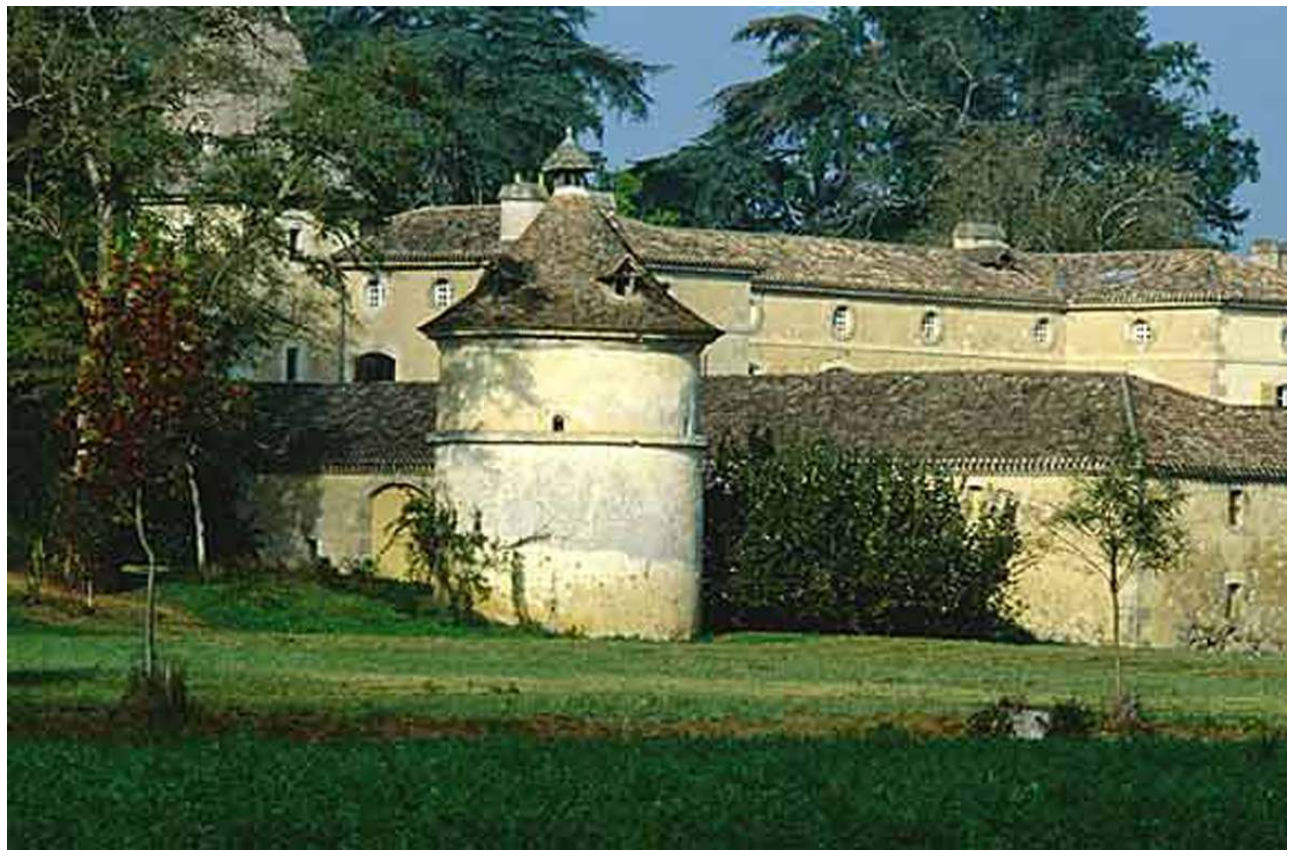

Moncrabeau. Pomarède. Château : vue prise du sud-est

Phot. Inv. B. Chabot ( I Inventaire général, ADAGP, 1997 


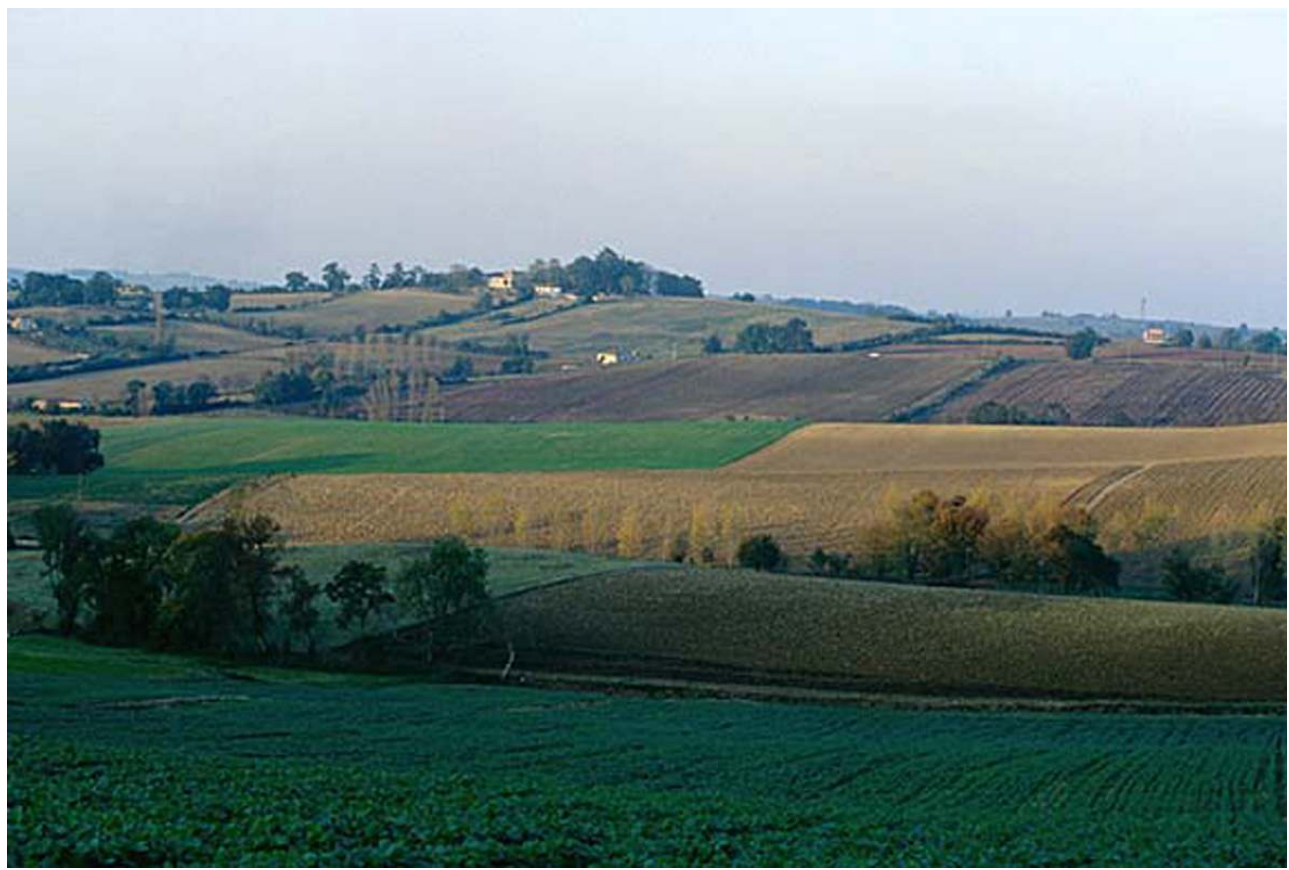

Francescas. Saint-Barthélemy. Manoir : vue d'ensemble du domaine de Saint-Barthélemy depuis le sud

Phot. Inv. H. Mousset @ Inventaire général, ADAGP, 1997

Figure 39

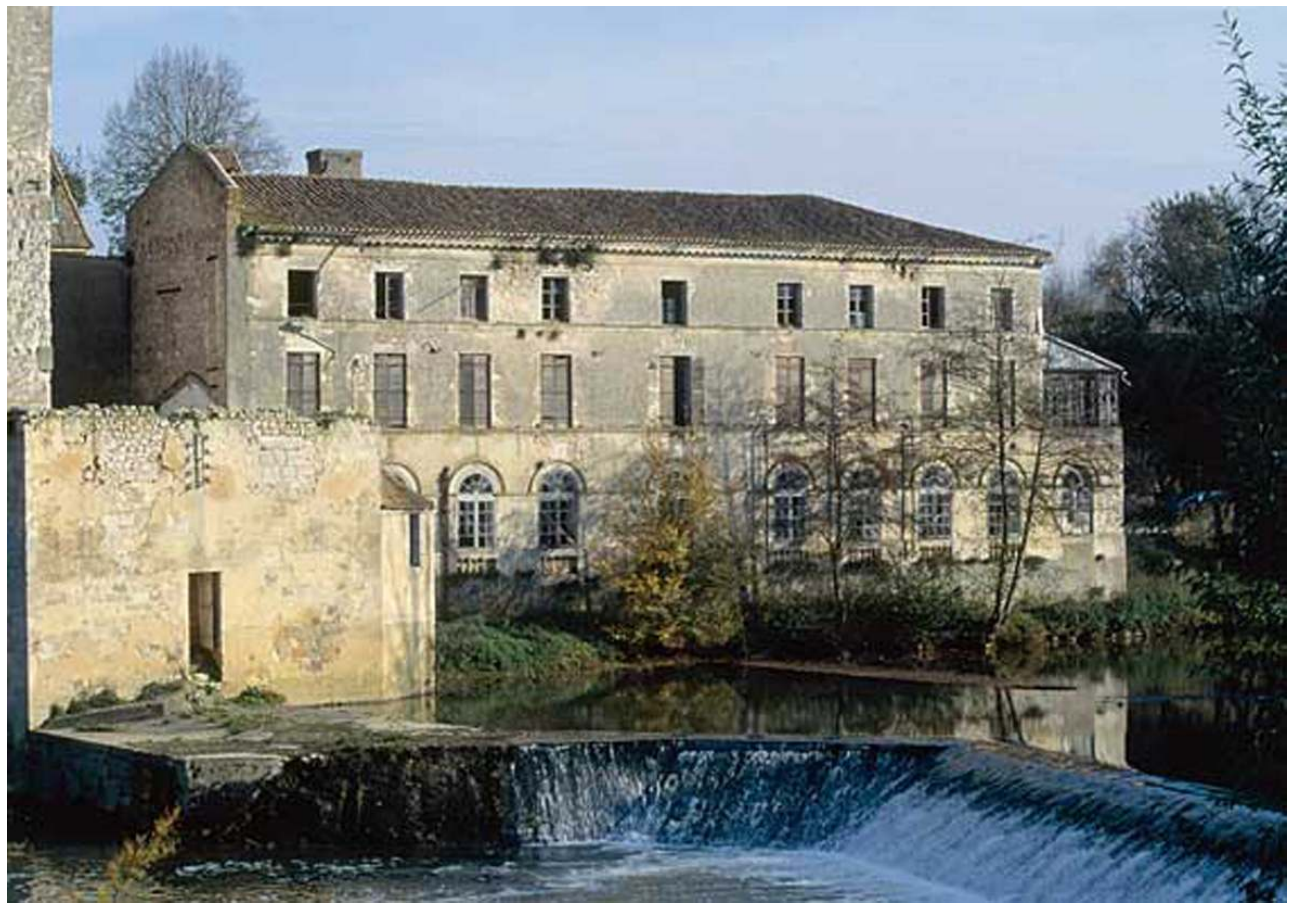

Nérac. Le Moulin de Barbaste. Moulin à blé, minoterie, dit les Tours de Barbaste. Bâtiment dit la maison d'Auriac

Phot. Inv. B. Chabot @ Inventaire général, ADAGP, 1994 


\section{Une source importante sur le paysage et son évolution} comprendre le paysage et son évolution: deux exemples de la vallée de la Baïse vont illustrer notre propos.

Figure 40

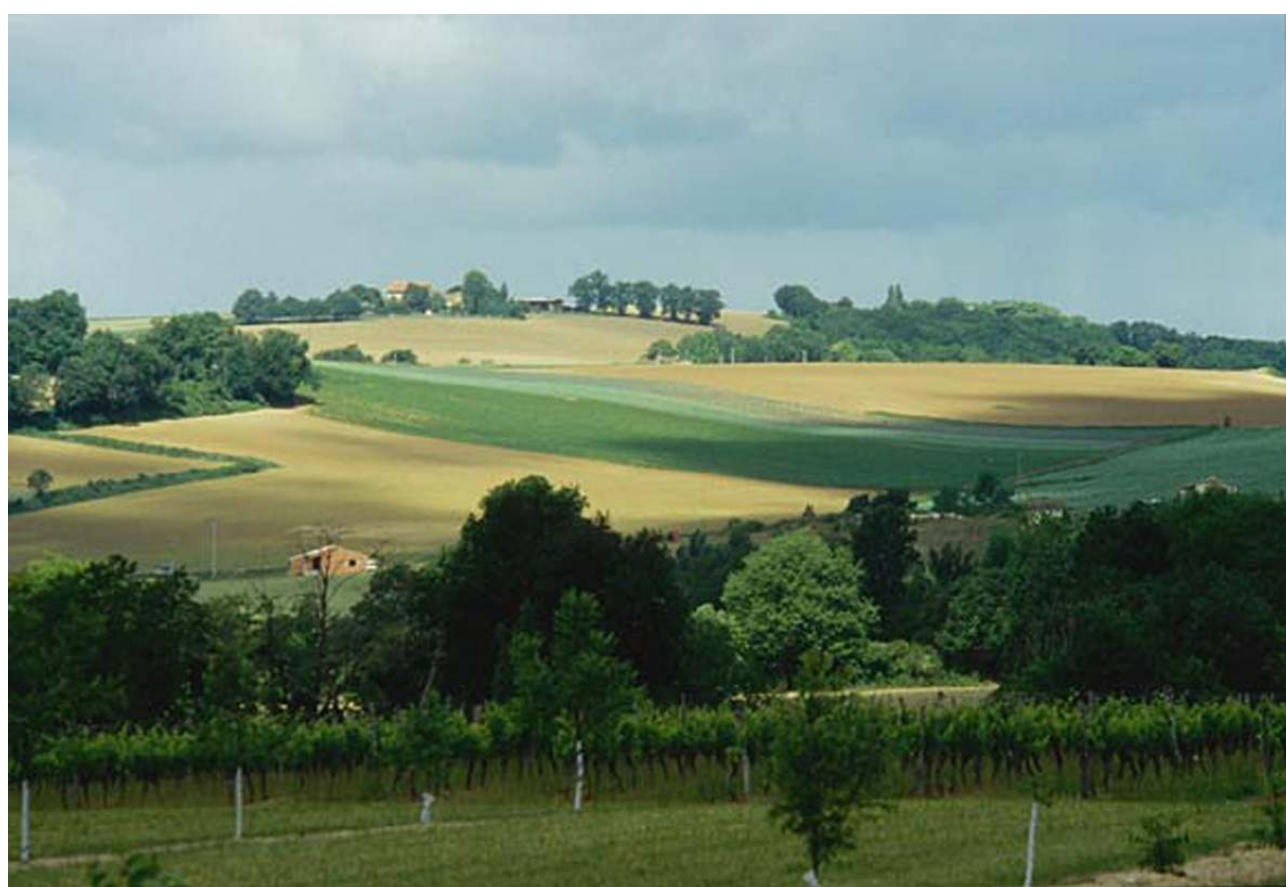

Lavardac. Paysage depuis la route de Lavardac à Feugarolles vers l'ouest Phot. Inv. B. Chabot @ Inventaire général, ADAGP, 1995

Le contraste naturel entre les coteaux du sud de la Garonne et les landes, séparées par la Gélise, est fortement accentué par leurs mises en valeur. Les coteaux offrent un paysage (fig. $\mathbf{n}^{\circ}$ 40) de vignes et de céréales, tandis que les landes étendent leur monoculture de pins. Fermes, châteaux, églises, moulins ponctuent régulièrement les coteaux, quand les landes se parcourent sur des kilomètres sans âme qui vive. L'étude des édifices et des paysages croisée avec les textes d'archives permet pourtant de dresser jusqu'à la seconde moitié du XIXe siècle un tableau beaucoup moins caricatural. Les landes ont été plus peuplées, comme le rappellent églises ou fermes aujourd'hui abandonnées; elles ont également été plus riches, grâce à l'exploitation des bois, des taillis, des landes, des labours complantés et surtout du chêne-liège. En revanche, les coteaux ne se sont vraiment spécialisés dans la céréaliculture qu'au XVIII ${ }^{\mathrm{e}}$ siècle et leurs puissantes minoteries sont en partie des agrandissements du XIX ${ }^{e}$ siècle. Au XVII ${ }^{e}$ siècle, par conséquent, les contrastes apparaissaient beaucoup plus nuancés entre ces deux secteurs 16 . 


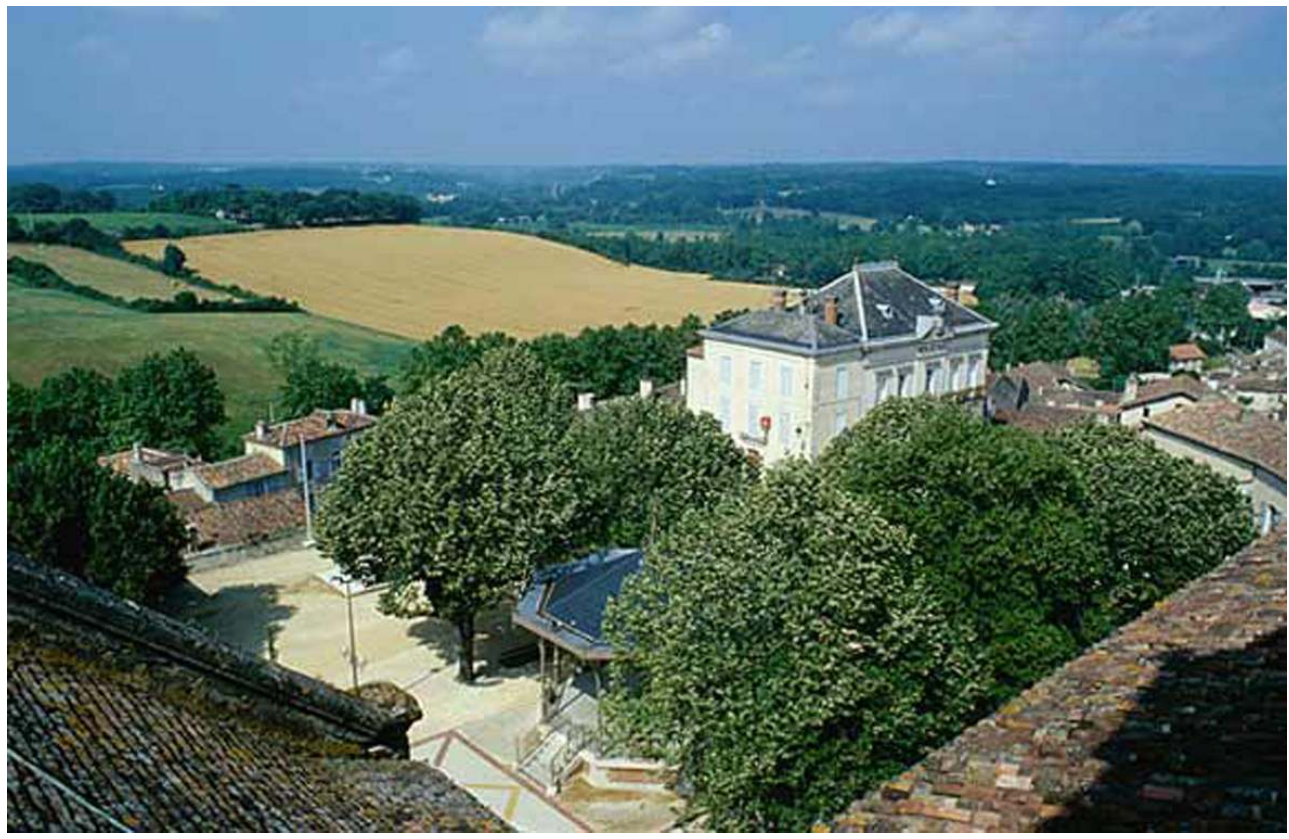

Mézin. Kiosque, hôtel de ville, monuments (vue prise du clocher)

Phot. Inv. B. Chabot @ Inventaire général, ADAGP, 1998

57 Mézin (fig. $\mathbf{n}^{\circ} \mathbf{4 1}$ ) se trouve près de la Gélise, entre landes et coteaux. A l'échelle de l'agglomération, l'ensemble des données collectées sur le bâti permet de comprendre l'évolution du bourg. Un premier noyau de peuplement s'est constitué autour du prieuré de bénédictins (la largeur de certaines rues s'explique par la présence des fossés de la première enceinte). A la fin du XIII ${ }^{e}$ siècle, le bourg s'est largement étendu, et inclut un couvent de cordeliers : l'édification des remparts en pierre de taille avec portes de ville, les vestiges de demeures en pierre de taille, l'extension de l'église prieurale et paroissiale donnent la mesure d'une croissance importante de la population et de l'aisance des habitants - les franchises, connues par sources écrites, dont les rois d'Angleterre, ducs d'Aquitaine, ont fait bénéficier les habitants concordent avec le bâti.

58 A l'époque moderne, les anciens fossés transformés en boulevards attirent les maisons les plus cossues, constructions nouvelles ou rénovations de maisons médiévales. Au XIX ${ }^{\mathrm{e}}$ siècle, l'industrie du liège et du bouchon s'installe à Mézin dans les espaces périphériques intra-muros restés jusque-là en jardins. L'importance des jardins, vastes espace libres, est essentielle ici comme dans nombre de petites villes jusqu'à la Révolution et trahit bien l'imbrication étroite entre l'agglomération et la campagne (fig. $\mathrm{n}^{\circ} \mathbf{4 2}$ ). 


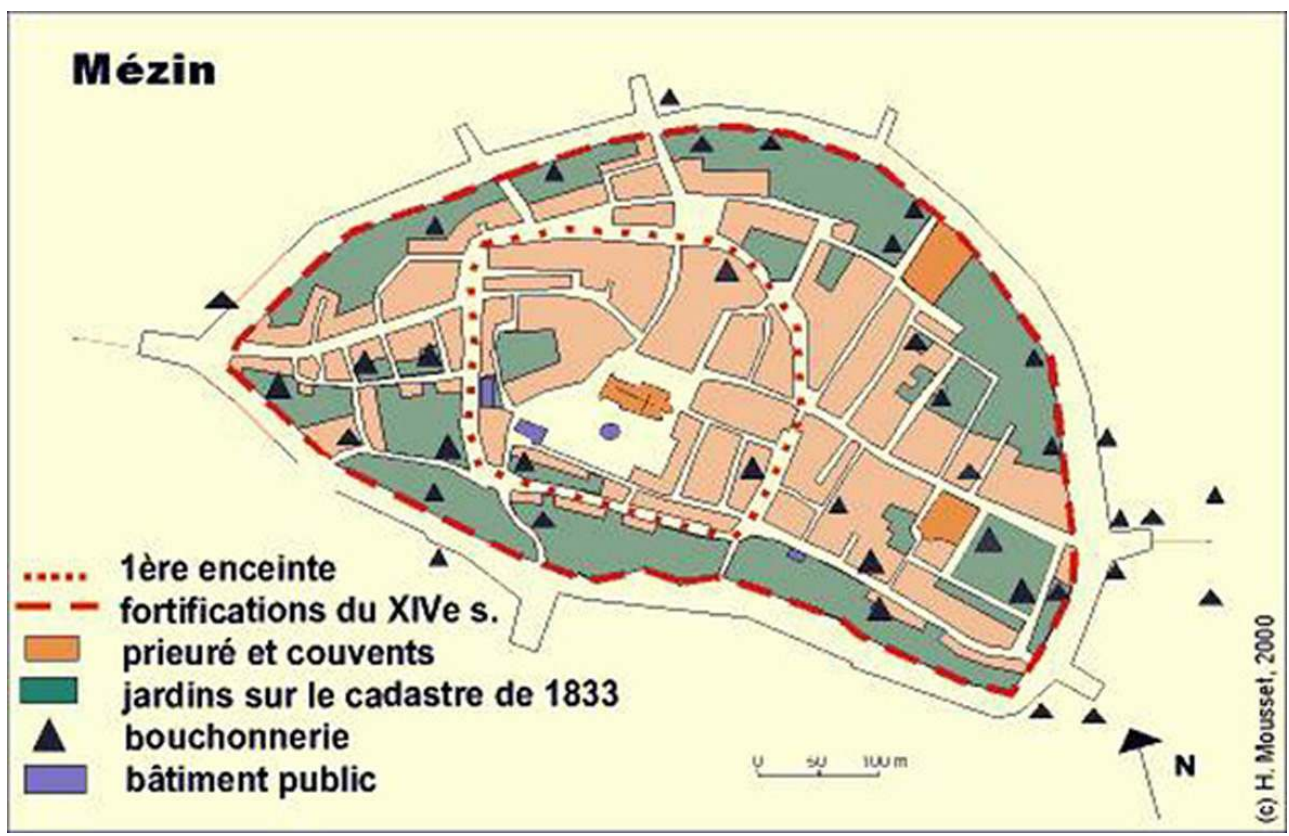

Plan de la ville de Mézin

Plan H. Mousset (C) Inventaire général, H. Mousset

$\mathrm{Du}$ fait qu'elles sont situées dans une fourchette chronologique, les informations collectées se lisent donc comme une source complémentaire des archives sur l'histoire rurale. En même temps, la prise en compte de l'espace, grâce à la localisation géographique, ramène à la notion de territoire, qui est à l'origine de cette enquête. L'étude de l'architecture et des paysages dans la longue durée confirme l'évolution constante des espaces ruraux, l'absence de fixité des bâtiments et des contextes agraires.

Divers, évolutifs, les territoires ruraux se composent - au-delà des habitations et des bâtiments d'exploitation - du maillage des paroisses, des réseaux de bourgs, des voies de communication et des industries complémentaires. Le principal intérêt de l'inventaire topographique est précisément cette approche généraliste d'un territoire, qui permet de dessiner les relations de tous ces éléments et leurs évolutions dans le temps.

\section{NOTES}

1. Participation de l'Etat (DRAC Aquitaine), du Conseil général de Lot-et-Garonne et de l'Europe, direction scientifique du service régional de l'inventaire en Aquitaine.

2. Notices Mérimée : 2780 / notices Palissy : 3237.

3. Site patrimonial du département du Lot-et-Garonne : http://www.cg47.fr/.

4. 1994-1999 pour la vallée de la Baïse et 1996-2003 pour la vallée du Lot. Menée par trois chercheurs permanents (A. Beschi et H. Mousset pour l'architecture et J.-P. Maisonnave pour les objets) et un photographe. Des stagiaires et aides ponctuelles ont participé à l'enquête. Il n'est 
sans doute pas inutile de préciser que, vu la brièveté des délais et la longueur des déplacements, il n'y a pas eu de retour sur le terrain, sauf exception. La sélection et les clichés photographiques sont immédiats. La compréhension du terrain par les enquêteurs et le souci de cohérence de l'ensemble se sont donc avérés essentiels.

5. Le repérage vise à discerner des familles d'individus à caractéristiques communes, que la sélection illustre par des dossiers plus détaillés. Voir Principes et méthode de l'inventaire général: http://www.culture.gouv.fr/culture/inventai/presenta/method.htm

6. Deffontaines, P. La Moyenne Garonne, Agenais, Bas-Quercy. Agen : Quesseveur, 1978 (facsimilé de l'édition de 1932). Luxembourg, Maurice. Géographie du département de Lot-etGaronne. Nérac: G. Couderc, 1954, p. 35-37.

7. Samazeuilh, J.-F. Dictionnaire géographique, historique et archéologique de l'arrondissement de Nérac. Toulouse : Eché ; Nérac: Pesquera, 1982 (fac-similé de l'édition de 1881). Delpont, H. Deux siècles d'économie en Albret. Agen: Ed. de la Société Académique d'Agen, 1983. Alis (Abbé). Histoire de la ville d'Aiguillon et de ses environs depuis l'époque gallo-romaine jusqu'à nos jours. Agen: Ferrau frères, 1895. La vallée du Lot et son environnement. Actes du XLIV e congrès d'études régionales 1992. Bordeaux: Fédération Historique du Sud-Ouest, 1994. Massip, L. Histoire de la ville et des seigneurs de Cancon en Agenais. Agen: Imp. Vve Lamy, 1891. Tholin, G. Etudes sur l'architecture religieuse de l'Agenais du X $\mathrm{X}^{\mathrm{e}}$ au XVI ${ }^{\mathrm{e}}$ siècle. Paris-Agen, 1874. Dubourg-Noves, P. Guyenne romane. Zodiaque, 1969 (Collection La nuit des temps). Bouliac, H. Inventaire des sites fortifiés du canton de Penne-d'Agenais. Mémoire de maîtrise, Toulouse, 1994. Simon, P. La société nobiliaire en Agenais de Raymond VII à la guerre de Saint-Sardos. Bordeaux III, 1994. Gardelles, J. Les châteaux du Moyen Age dans la France du Sud-Ouest. Genève, 1972. Delletry, A. Architecture civile médiévale à Penne-d'Agenais. Mémoire de maîtrise, université Paris I, 2002. Marin, A. Une maison du XIII ${ }^{\mathrm{e}}$ siècle à Tournon-d'Agenais, rue de la Citadelle. Bulletin monumental, t. 160, 2002, p. 304-306. Clemens, J. Géographie historique de la maison à empilage en Agenais. Colloque de Bazas, 1978. CNRS/CRPB, 1979, p. 161-167. Etudes sur les maisons à empilage de poutres dans le Nord Agenais. Bull. du Pastourais, n 7, 1979. Fray, F. Construction en empilage dans le Nord Agenais. L'information d'Histoire de l'Art, 1974, p. 213-219. Pour une bibliographie exhaustive sur l'habitat médiéval, voir le site Internet de la Société archéologique du Midi :

http://www.societes-savantes-toulouse.asso.fr/samf/grmaison/gtmaison1.htm

8. Arch. dép. Lot-et-Garonne, série $1 \mathrm{Q}$.

9. Tâche en cours. Cela suppose dès la collecte un traitement statistique des données cohérent sur l'ensemble du programme. Les données du repérage sont traitées par communes sous forme de tableaux. Vue l'échelle de l'enquête (89 communes), les données à la commune sont tout à fait significatives.

10. Sur ce sujet, voir : Mousset, H. Matières à bâtir de Lot-et-Garonne. Le Festin, $n^{\circ} 46,2003$, p. 40-47.

11. Voir fig. $\mathrm{n}^{\circ} 16$.

12. Voir fig. $n^{\circ} 28$.

13. La tradition orale rapporte que la vente de la récolte d'une année de pruneaux permettait, au tournant des $\mathrm{XIX}^{\mathrm{e}}$ et $\mathrm{XX}^{\mathrm{e}}$ siècles, de construire une maison de ce type (informations recueillies à Sainte-Livrade-sur-Lot et Monclar).

14. Tout en assurant la cohérence de l'étude sur le territoire, ces cadres sont donc restés souples et évolutifs, ouverts aux réalités imprévues.

15. Ces bâtiments rares sont donc proportionnellement sur-sélectionnés et mieux représentés dans les bases de données.

16. Pour une présentation plus complète, voir : http://www.inra.fr/dpenv/moussc47.htm 


\section{RÉSUMÉS}

Un inventaire du patrimoine a été réalisé dans dix-sept cantons ruraux le long du Lot et de la Baïse. Ce territoire s'étend sur plusieurs secteurs géographiques et se caractérise par un habitat et des paysages variés. L'étude des relations entre l'habitation et les dépendances agricoles a permis d'envisager les systèmes agraires et leur évolution. En outre, l'ensemble des éléments bâtis du territoire ayant été pris en compte, cet inventaire rend possible une approche de l'histoire des paysages ruraux.

An heritage survey has been undertaken for seventeen rural districts along the Lot river and the Baïse river. This area covers several geographical sections and can be characterized by a diversified dwelling pattern. The study of the connections between dwelling and agricultural outbuildings allows us to address the question of the agrarian systems and their evolution. Moreover, all the buildings of the area having been considered, this survey enables us to draw up an historical outline of the rural landscapes.

INDEX

Mots-clés : Lot, Baïse, habitat rural, dépendances agricoles, système agraire, paysage, Lot-etGaronne, pigeonnier, four à prunes, grange-étable, logis, séchoir à tabac

\section{AUTEUR}

\section{HÉLÈNE MOUSSET}

Conservatrice du patrimoine, Service régional de l'archéologie, Direction régionale des affaires culturelles d'Aquitaine. helene.mousset@culture.gouv.fr 